\title{
SITUAÇÃO ATUAL DO CONTROLE BIOLÓGICO NO MANEJO INTEGRADO DE MOSQUITOS (DIPTERA: CULICIDAE)
}

\author{
LUCIANA MARQUES CUBA
}

\begin{abstract}
Dissertação de mestrado apresentada ao Departamento de Epidemiologia da Faculdade de Saúde Pública da Universidade de São Paulo para a obtenção do Grau de Mestre.

Área de Concentração: Epidemiologia
\end{abstract}

ORIENTADOR: PROF. DR. DELSIO NATAL

São Paulo

2004 


\section{AGRADECIMENTOS}

Dedico este trabalho primeiramente a Deus, pela oportunidade que me foi concedida.

Os meus mais sinceros agradecimentos ao Prof. Dr. Delsio Natal pela orientação prestada e pelo incentivo permanente na realização deste trabalho.

Ao CNPq (Conselho Nacional de Desenvolvimento Cientifico e Tecnológico), pela bolsa de estudos concedida durante parte deste estudo.

Aos amigos do laboratório de culicideos e triatomineos da Faculdade de Saúde Pública - USP, pela apoio durante este trabalho.

Aos meus pais e amigos, pelo apoio incondicional durante todo esse percurso. 


\section{RESUMO}

Cuba LM, Situação do controle biológico no manejo integrado de mosquitos (Diptera:Culicidae). São Paulo; 2003. [Disscrtação dc Mcstrado - Faculdadc dc Saúdc Pública da USP].

$\mathrm{O}$ controle de mosquitos à base de inseticidas químicos tem encontrado dificuldades crescentes de utilização, especialmente nos últimos anos. $\Lambda$ s razões são basicamente, $\mathrm{o}$ alto custo de desenvolvimento e comercial desses compostos sintéticos, a agressão ambiental devido a inespecificidade, persistência ambiental, os riscos operacionais e a crescente resistência a esses compostos. Essas razões tem levado a um grande esforço para o desenvolvimento e aperfeiçoamento de alternativas eficazes e seguras, fatores que podem estar relacionados ao controle biológico. O controle biológico consiste na utilização de inimigos naturais diretamente ou através de metabólitos, estratégias encontradas freqüentemente na natureza, que foram deixadas de lado, com o surgimento do "milagroso" controle químico. Este trabalho tem por objetivo atualizar os conhecimentos sobre a importante questão da alternativa biológica no controle integrado de mosquitos (Diptera:Culicidae) de importância epidemiológica. Destacam-se as estratégias de predação, parasitismo e os agentes microbianos patogênicos como as formulaçð̃es comerciais do gênero Bacillus. A potencialidade de uso de agentes diversos e a importância do referido biocontrole nos programas nacionais, bem como a produção e aplicação em massa desses agentes são abordados com detalhes nessa monografia.

Descritores: controle biológico, mosquitos, culicídeos. 


\section{ÍNDICE}

1. INTRODUÇÃO 1

1.1 Ordem Díptera 1

1.2 Familia Culicidae 1

2. OBJETIVOS 7

$\begin{array}{ll}2.1 \text { Objetivo Geral } & 7\end{array}$

$\begin{array}{ll}2.2 \text { Objetivos Especificos } & 7\end{array}$

3. MÉTODOS 8

4. MANEJO INTEGRADO DE PRAGAS (MIP) 10

5. OCONTROLE 14

6. CONTROLE BIOLOGICO 16

$\begin{array}{lr}\text { 7. TIPOS DE CONTROLE BIOLOGICO } & 18\end{array}$

$\begin{array}{ll}\text { 7.1 Fatores Ligados a Interação entre Populações } & 18\end{array}$

$\begin{array}{llr}7.1 .1 & \text { Predação } & 18\end{array}$

$\begin{array}{llr}7.1 .2 & \text { Parasitismo } & 19\end{array}$

7.2 Fatores ligados a Competição Intra - específica 21

7.3 Fatores Ligados à Toxinas ou Princípios Tóxicos 21 
8. PREDACAO 23

8.1 Copépodos 23

$\begin{array}{lr}\text { 8.2 Peixes } & 27\end{array}$

8.3 Outros Invertebrados

9. PARASITISMO 38

$\begin{array}{ll}9.1 \text { Nematodas } & 38\end{array}$

$\begin{array}{ll}9.2 \text { Microposridio } & 44\end{array}$

\begin{tabular}{l}
9.3 Fungos \\
\hline
\end{tabular}

10. BACILLUS SP

11. ESTERELIZAÇÃO E MANIPULAÇÃO GENÉTICA 69

12. O USO DE PLANTAS

$\begin{array}{ll}\text { 13. DISCUSSÃO } & 71\end{array}$

$\begin{array}{ll}\text { 14. CONCLUSÃO } & 77\end{array}$

15. REFERÊNCIAS 


\section{INTRODUÇÃo}

\subsection{Ordem Diptera}

É muito rica a nomenclatura popular relacionada com os dipteros. Afinal são eles que mais azucrinam a vida de qualquer mortal, sejam no descanso, nos passeios, pescarias, etc. ( BUZZI,1985)

Esta ordem é de grande importância para o homem tanto do ponto de vista médico, veterinário ou agrícola. Tanto o homem como os animais são vitimas do ataque de dípteros. ( BUZZI, 1985).

Desempenham, um papel de grande importância na economia humana.Os mosquitos são responsáveis pela transmissão ao homem de agentes causadores de varias doenças(CARRERA, 1963).

Varias espécies de mosquitos transmitem doenças como a malaria, febre amarela, filarioses, leishimanioses, micróbios causadores do tifo e desinterias. Do ponto de vista agrícola os danos causados por estes insetos são menores.( BUZZI, 1985)

\subsection{FAMÍLIA CULICIDAE}

Classificados como pertencentes à ordem díptera, família culicidae, esses insetos possuem corpo alongado, asas estreitas, corpo rico em escamas e cerdas e patas longas.

Nesta família encontram-se os mosquitos e pernilongos sugadores de sangue, apenas as fềmeas que possuem probócide alongada, com componentes filiformes e rígidos próprio para furar a pele do homem e sugar sangue, sendo que as proteínas do 
sangue serão utilizadas no desenvolvimento dos ovaríolos. Dentre eles devem ser destacadas as espécies dos gêneros Culex, Anopheles e Aedes, destacando -se o Aedes aegypti vetor da dengue, o Culex quinquefasciatus causador de grande incomodo nas grandes cidades, Anopheles sp. vetores da malária.

Entre o grupo de dípteros hematófago, os culicídeos representam o grupo mais abundante e de maior importância medico-epidemiológica e são tão numerosos que se encontram em variadas condiçðes ecológicas (FONSECA e col. 1988).

Os imaturos de culicídeos, ovos, larvas e pupas, necessitam de coleções líquidas paradas ou com pouco movimento para seu desenvolvimento, até atingirem as formas adultas. Essas coleções líquidas são conhecidas como criadouros e classificam-se em naturais ou artificiais, permanentes, semi-permanentes ou transitórias. A importância ecológica de tal classificação está relacionada à capacidade de sobrevivência e de adaptação das formas imaturas desses mosquitos (FORATTINI 1962). O conhecimento da biologia e capacidade de adaptação dos culicídeos nesses criadouros é de extrema importância para eficiência de seu controle; assim como das características climáticas, sócio-economicas e culturais da região a ser tratada.

Os ovos são colocados isolados ou aglutinados em jangadas.São depositados na água estagnada (Culex, Anopheles), nas paredes de recipientes (Aedes aegypti e Ae. albopictus) e em depressð̃es no solo potencialmente inundáveis (Aedes e Psorophora).

Quando eclodem as larvas passam por quatro estágios larvais até se tornarem pupas. A fase pupal é relativamente curta. Quando a pupa esta madura, mantém-se na superficie da água. Em certo momento, o exoesqueleto de quitina se rompe e o adulto emerge. O raio de vôo dos adultos varia grandemente de acordo com a espécie. 
As formas imaturas de mosquitos, por viverem e se desenvolverem em ecossistemas aquáticos estão submetidas à ação de diversos fatores bióticos e abióticos. Tais fatores interferem na flutuação e/ou regulação destas populaçð̃es $e$ conseqüentemente seu conhecimento reveste-se de grande importância epidemiológica (FORATTINI, 1962).

O papel dos fatores bióticos na comunidade de formas imaturas de culicídeos foi discutido por HOBBS e MOLINA (1983), LAIRD (1988), ORR e RESH (1989) e SAVAGE e col. (1990), em relação às plantas aquáticas (macrófitas); SAVAGE e col. (1990), em relação ao fitoplâncton; SANTOS e col. (1997) observaram a predação por copépodos; JAROSNKI e AXTELL (1982) estudaram a infectividade por fungos.

Segundo BECKER (1992), as questões relacionadas à saúde e ambiente estão atualmente se tornando uma preocupação constante não só daqueles que se dedicam às ciências ambientais, mas dos mais variados segmentos da sociedade.

Tanto o aparecimento de novas doenças infecciosas quanto o ressurgimento de antigos problemas de Saúde Pública, segundo especialistas, podem estar ligados a vários fatores, destacando-se entre eles: alterações ambientais devido ao processo de industrialização e às novas tecnologias aplicadas à agricultura, irrigação, construção de barragens, uso de terras, uso de recursos hídricos, desmatamento, problemas econômicos; urbanização falta de saneamento básico, mudanças de comportamento humano, mudanças climáticas, etc. ( COOSEMANS e MOUCHET 1990; SCHOFIELD 1990; SERVICE 1991; KNUDSEN e SLOOFF 1992; MORSE 1995).

Os problemas epidemiológicos, decorrentes da proliferação intensa de mosquitos, constituem preocupação constante por parte dos serviços sanitários nos grandes centros 
urbanos do mundo, principalmente em regiőes com condições de saneamento básico precárias (URBINATTI 2000).

No Brasil, nos últimos anos uma das grandes preocupações das autoridades de saúde e da população em geral tem sido as epidemias de dengue, que tem atingindo toda a população não selecionando classe social, faixa etária, raça e sexo. Desafiando a todos, e crescendo cada vez mais.

Culicídeo é um grupo de insetos conhecidos de longa data pelos problemas de saúde que causam ou intermediam ao homem e animais domésticos, quer devido às picadas e reaçðes alérgicas, quer pela transmissão de viroses, protozooses e filarioses. Têm sido combatidos por todas as gerações de inseticidas, dos organo-clorados e fosforados aos piretróides, quase sempre com surgimento dos fatores adversos como a resistência e o impacto ambiental. Em nível de controle biológico, os culicídeos têm sido alvo de pesquisas com predadores e patógenos diversos (Neto, 1985).

No Brasil a resistência dos suscetíveis e o impacto ambiental que eles determinam tem levado a procura de outras alternativas para o controle, como a substituição dos larvicidas químicos (Fleming, 1983). Os programas atuais de controle de espécies vetores ou provocadoras de incômodo dependem quase que exclusivamente de agentes químicos, nas áreas rurais, agricolas e também urbanas.

Dentro desse contexto, é importante ressaltar que a competição, o parasitismo e principalmente a predaçăo têm sido apontados como os principais fatores bióticos responsáveis pela redução populacional de formas imaturas de mosquitos.

O controle de pragas à base de inseticidas químicos tem encontrado dificuldades crescentes de utilização, especialmente nesta ultima década. As razões são basicamente, 
o alto custo destes compostos sintéticos e a agressão ambiental devido a inespecificidade, persistência no ambiente e riscos operacionais. Isto tem levado a um grande esforço para o desenvolvimento de alternativas eficazes e seguras, relacionadas ao controle biológico de pragas (WHO, 1979).

No século vinte os inseticidas sintéticos vieram substituir o controle natural de pragas de interesse em Saúde Pública, representando uma nova tecnologia de controle, mas também trouxeram uma série de novos prejuizos e riscos que não eram totalmente conhecidos, como a toxicidade e não especificidade. Há algum tempo, novas questões relativas a esses riscos e prejuízos têm surgido, especialmente as que estão ligadas à qualidade do ambiente, como a contaminação de água por produtos químicos ar, solo e alimentos.

Outra desvantagem do controle químico convencional é o aparecimento de cada vez mais espécies resistentes, e diante desse problema o excessivo uso desses produtos em busca de um controle tem resultado a evidente contaminação ambiental. O controle biológico baseia-se no emprego de inimigos naturais, tendo em vista a redução eficaz da população de mosquito, ou seja, neste contexto a atividade de controlar passa a ser vista como um processo artificial induzido ou implantado pelo homem com objetivo bem definido. É dessa maneira que o conceito pode ser contextualizado como sendo: “ a destruição ou supressão de animais ou plantas indesejáveis através da introdução ou da manipulação reforçada de seus inimigos naturais" (SCHRIEBER \& JONES, 2000); ou referindo-se mais especificamente aos culicídeos: "o controle biológico se baseia no emprego de inimigos naturais ou toxinas biológicas com vistas a reduzir eficazmente a população de mosquitos" ( OMS, 1984). 
Em vista dessas dificuldades surgidas em várias partes do mundo nas tentativas de controlar mosquitos apenas com a utilização de métodos químicos, e diante das vantagens de um controle integrado a Organização Mundial de Saúde recomenda o controle biológico dentro de um programa integrado ao controle químico convencional ( WHO, 1981). A utilização de predadores naturais é uma dessas alternativas, de controle integrado. Muitos dados sobre a alimentação de organismos predadores baseados fundamentalmente em larvas de mosquitos são de natureza qualitativa, indicando a existência real de muitos inimigos naturais de larvas de mosquito. Isto portanto permite uma estimativa quantitativa dos efeitos da predação sobre a redução e regulação do número de larvas de mosquito (MIJARES, 1985). Por outro lado, a introdução de espécies exóticas, para esse fim, pode ter impacto adverso sobre a ecologia local (WHO, 1982) sendo por isso necessário à investigação de agentes autóctones. 


\section{OBJETIVOS}

\subsection{Objetivo geral}

Caracterizar o controle biológico de mosquitos discutindo a sua importância.

\subsection{Objetivos específicos}

Verificar os tipos de controle biológico com potencial de utilização no controle de culicídeos;

Levantar informaçðes sobre o uso do controle biológico nas Américas, com enfoque no Brasil;

Identificar os agentes de controle biológico mais adequados para serem utilizados em programas de controle no Brasil, levando-se em consideração as principais espécies de culicídeos vetores e as condições ambientais;

$>$ Recomendar estratégias de inserção do controle biológico em programas de controle de culicídeos no Brasil. 


\section{MÉTOdO}

A pesquisa consiste de um levantamento bibliográfico, abrangendo o periodo de 1979 a 2001. Foram consultadas as bases relacionadas a seguir:

Medline

Lilacs

Life Science

Cab Health

Biological Abstract

Agriscab

Os descritores foram:

Culicídeos $\mathrm{x}$ controle $\mathrm{x}$ biológico

Culicídeos $\mathrm{x}$ controle $\mathrm{x}$ biológico $\mathrm{x}$ predação

Culicídeos $\mathrm{x}$ controle $\mathrm{x}$ biológico $\mathrm{x}$ artrópodes

Culicídeos $\mathrm{x}$ controle $\mathrm{x}$ biológico $\mathrm{x}$ vertebrados

Culicídeos $\mathrm{x}$ controle $\mathrm{x}$ biológico $\mathrm{x}$ Bacillus

Culicideos $\mathrm{x}$ controle $\mathrm{x}$ biológico $\mathrm{x}$ patógenos

Culicideos $\mathrm{x}$ controle $\mathrm{x}$ biológico $\mathrm{x}$ vírus

Culicideos $\mathrm{x}$ controle $\mathrm{x}$ biológico $\mathrm{x}$ fungos

Culicídeos $\mathrm{x}$ controle $\mathrm{x}$ biológico $\mathrm{x}$ protozoários

Culicídeos $\mathrm{x}$ controle $\mathrm{x}$ biológico $\mathrm{x}$ vermes

Culicídeos $\mathrm{x}$ controle $\mathrm{x}$ biológico $\mathrm{x}$ América

Culicídeos $\mathrm{x}$ controle $\mathrm{x}$ biológico $\mathrm{x}$ Brasil 
Optou-se por fazer levantamento a partir de 1979 , por esta ser a data do trabalho de Axtell, considerado um marco na consolidação do manejo integrado de pragas aplicado ao controle de mosquitos. Além dos trabalhos indexados nas bases pesquisadas, foram consultados outros citados nos artigos consultados. Sempre que necessário, foram incluídos artigos publicados em data anterior ao ano de 1979. 


\section{MANEJO INTEGRADO DE PRAGAS (MIP)}

Os fracassos do controle químico e os efeitos tóxicos que estes produtos causam nos ecossistemas, levaram os pesquisadores a estudarem em todos os azimutes outros meios de controle, notadamente a utilização de bactérias, vírus, fungos, nematodes, predadores, no quadro do controle biológico. Entretanto, é evidente que os produtos quimicos continuam sendo elementos essenciais na maioria dos programas anti-vetoriais previstos e, em consequência, torna-se mister encontrar métodos para o emprego mais eficaz, econômico e seletivo desses produtos (GEBARA, 1987).

Desde fins do século XIX e começo do século XX, quando ficou comprovado o envolvimento de vetores na transmissão de doenças, as recomendações para a organização e o combate incluíam, a orientação da população, o uso de inseticidas, proteção pessoal e o estudo das possibilidades de controle biológico através de peixes larvófagos (OMS, 1983).

O objetivo do controle integrado é harmonizar os diferentes métodos de controle e em conseqüência reduzir o número de tratamentos químicos. Assim, o controle químico é usado somente onde e quando necessário e de maneira a ser o menos prejudicial possível ao meio ambiente (GEBARA,1987).

Utilizaremos a publicação de AXTELL, (1979) como um marco na consolidação do MIP aplicado ao controle de mosquitos. A implementação do MIP em sistemas de produção de alimentos teria surgido bem antes. Aplicado em fazendas e tendo como meta diminuir perdas provocada pelo ataque de pragas, o MIP, segundo definição de 
Smith \& Reynolds teria por objetivo: "implantar um sistema de manejo de pragas de pragas que se utiliza todas as técnicas adequadas, de maneira compatível para reduzir a sua população e mantê-la em nível abaixo visando à diminuição dos prejuízos econômicos.

Segundo AXTELL,(1979), manejo integrado de pragas (MIP) é uma evolução na sofisticação e conceitualização das estratégias humanas de controle de pragas. Isto reflete em uma evolução de termos como: controle de pragas, para manejo de pragas e finalmente manejo integrado de pragas.

O seletivo e criterioso uso de inseticidas combinados com medidas biológicas e a própria pratica do manejo mecânico constituem uma parte integral para o sucesso nos programas de controle de mosquitos (MARAMOROSCH, 1985).

$O$ que se concebe atualmente é que o MIP se fundamenta em princípios ecológicos, dentro de uma abordagem interdisciplinar, utilizando-se estratégias de manejo de ecossistemas, empregando-se medidas práticas, efetivas, econômicas e ao mesmo tempo, protetoras de saúde e do ambiente. MIP não é aplicado apenas ao controle de mosquitos, mas também, para qualquer outro tipo de vetores mecânicos ou biológicos, de interesse em Saúde Pública ou Veterinária. Além dessas áreas, essa maneira moderna de enfrentar problemas entomológicos se estende para agricultura e para silvicultura.

Seguindo esta seguinte direção AXTELL,(1979) desdobra os termos, definindo o sentido de cada palavra para poder explicar melhor esse conceito: I-manejo seria o ato, a arte ou a maneira de manipular, controlar, administrar ou conduzir negócios, ou seja, o uso criterioso de meios para se conquistar um fim. Assim o termo manejo não 
teria por objetivo erradicar a praga, mas sim, manter sua população em um nível aceitável para o público. Axtell, deixa explicito que o uso do termo manejo é bastante adequado para comunicação com o público, por não gerar falsa expectativa de solução definitiva do problema. I- integrado significa compor um todo, unir, incorporar em uma grande unidade. Transmite a idéia de mistura criteriosa de partes na composição do todo. Não se refere meramente ao uso das diferentes partes, pois o todo resultante é maior que a somatória das partes. Quanto ao problema de pragas o termo "integrado" refere-se à criteriosa mistura de habilidades (de diferentes disciplinas) e de diferentes métodos de controle. No manejo de uma população de mosquitos, deve-se incluir não apenas a entomologia, mas também a engenharia, a ecologia, a economia, etc. IIIPraga - seria um organismo prejudicial ao homem. Nesse conceito, os mosquitos, seriam pragas porque: picam, são causadores de incômodo e transmitem doenças. Uma população excessiva de mosquitos produz efeitos adversos no crescimento econômico de uma área, constituindo assim, um exemplo típico de praga.

Baseado em princípios ecológicos e metodologias multidisciplinares integradas, $\mathbf{e}$ no desenvolvimento de arranjos do ecossistema, o MIP atua de forma prática, efetiva, econômica, protegendo tanto a saúde pública como o meio- ambiente.

Na visão moderna MIP, entende-se a disponibilidade de uma enorme variedade de alternativas de controle dentre as quais, deve-se selecionar as estratégias mais adequadas, visando cumprir determinado objetivo no combate às pragas. Quando o objetivo é combater mosquitos, pode dividir o grande leque de possibilidade ou alternativas do MIP nos seguintes segmentos: controle químico- entende-se por esse tipo de controle aplicação de produtos de natureza química, visando reduzir uma 
população de culicídeo, de maneira a impedir a transmissão de doença ou evitar incômodo; ordenamento do meio e educaçåo -compreende planejamento, organização, realização e vigilância de atividades para a modificação e/ou alteração de fatores ambientais, ou respectivas interações com 0 homem, com o propósito de diminuir ao mínimo a propagação de vetores e reduzir o contato entre o homem, o vetor e o agente; e o controle biológico, esses métodos se baseiam no emprego de inimigos naturais e de toxinas biológicas, com objetivo de reduzir a proporção de mosquitos (OMS, 1977). 


\section{O CONTROLE}

Podemos dizer que a primeira forma de controle de insetos em geral foi à mão, para espantar ou mesmo matar os agentes de incomodo seja ele pela sua picada ou pelo barulho incomodo e em seguida tivemos a fumaça como repelente.

Durante muito tempo o homem buscou métodos naturais que estavam ao seu alcance para se proteger de insetos. Mas com o surgimento dos produtos químicos após a Segunda grande guerra esses métodos foram deixados de lado.

No século vinte os inseticidas sintéticos vieram substituir o controle natural de pragas que afetam a população, representando uma nova tecnologia de controle, mas também trouxeram uma série de novos prejuizos e riscos que não eram totalmente conhecidos, como a toxicidade e não especificidade. O controle químico foi "encantador" no inicio, pois não se dimensionava os danos que ele poderia causar em um futuro próximo. O primeiro grande milagre químico foi o DDT e seu sucesso na primeira metade do século XX, ultrapassou a década de 50 e as seguintes. Assim houve uma sucessão de novos produtos cada vez mais fortes e menos seletivos com a passar dos anos.

O uso abusivo do controle químico teve como resultado o desenvolvimento da resistência. A resistência a inseticidas é definida pela Organização Mundial de Saúde como uma característica herdável, portanto genética, que confere um aumento na tolerância a um pesticida, ou grupo de pesticidas, de modo que os indivíduos resistentes sobrevivem à concentração dos componentes que seriam normalmente letal para as espécies (WHO, 1992). Portanto, um dos grandes desafios que se colocam hoje para os 
entomologistas envolvidos com os programas de controle, consiste em prever o desenvolvimento ou ao menos, retardar o estabelecimento da resistência a novos inseticidas (BRACCO, 1998).

O futuro do controle de mosquitos vetores depende do sucesso de três diferentes medidas: tratamento de doenças com drogas e vacinação; prevenção das doenças com vacinação; e implementação de medidas para o controle (MOROSCH, 1985). 


\section{CONTROLE BIOLÓGICO}

Apesar dos mosquitos adultos serem também controlados por outras espécies em condiçães naturais, é durante o período de vida imatura que se concentra todo o conhecimento da alternativa de MIP. Devido à distribuição dispersa dos adultos, torna-se muito dificil imaginar uma forma de controle que fosse operacionalmente prática ou eficaz no combate às formas aladas. De maneira diferente, os imaturos estando limitados às coleções aquáticas que geralmente são bem definidas oferecendo um leque amplo de possibilidades de controle através de agentes biológicos.(NATAL, 2000)

Pode-se dizer que o controle biológico irá se processar na natureza independentemente da intervenção humana. Nesse caso as populações de mosquito são reguladas por um processo natural. Nessa direção, uma variedade de organismos, incluindo-se competidores, parasitas e predadores controlam as populaçð̌es de mosquitos. Em ambientes equilibrados e na ausência de distúrbios, esses mecanismos reguladores estabelecidos nos criadouros, podem manter a população adulta de culicídeos abaixo de um limiar crítico, impedindo que vetores competentes possam manter endemias ou gerar epidemias. (NATAL, 2000)

Convém ressaltar que nesse contexto a atividade de controle passa a ser vista como um processo artificial induzido ou implantado pelo homem, com um objetivo bem definido, que é de baixar a densidade dos culicídeos. Dessa maneira podemos conceituar como sendo: “ a destruição ou supressão de animais ou plantas indesejáveis através da introdução ou da manipulação reforçada de seus inimigos naturais"(SCHRIEBER \& JONES, 2000). Referindo-se mais especificamente aos culicídeos: "o controle biológico 
de baseia no emprego de inimigos naturais ou toxinas biológicas com vistas a reduzir eficazmente a população de mosquitos"(OMS, 1984).

O controle biológico pode apresentar as seguintes vantagens e desvantagens; segundo SCHRIEBER \& JONES,(2000): vantagens - 1. Atuação, o agente de controle afeta uma espécie ou pelo menos um grupo taxonômico mais amplo e definido, com pouco ou nenhum efeito sobre organismos não alvos; 2. Efeitos sobre o ambiente seriam menos prejudiciais quando comparados ao controle químico; 3 . Reciclagem quando ocorre representa uma redução permanente da população da praga. Desvantagens: 1. Introdução de espécies exóticas - representa risco à fauna local, podendo gerar desequilibrios; 2 . Problemas técnicos- surgem principalmente em relação ao transporte, formulação e aplicação; 3. Produção em massa - geralmente de dificil obtenção; 4. Recursos humanos- a sua aplicação exige conhecimento de dinâmica populacional e requer especialista em ecologia nem sempre disponível em áreas remotas endêmicas ou epidêmicas; 5. Especificidade - embora seja uma vantagem por não atingir outros organismos, gera problema, pois se torna necessário encontrar agentes específicos para os diferentes grupos taxonômicos; 6 . Investimento - geralmente maior no início quando comparado ao controle químico; 7. Pesquisa - quando destinada ao estudo de novos agentes com potencial o uso geralmente é demorado para se chegar a algum resultado; 8. Uso - as aplicaçðes são geralmente mais difíceis quando comparados ao emprego de inseticidas. 


\section{TIPOS DE CONTROLE BIOLÓGICO}

Nos últimos anos tem aumentado o interesse pelo desenvolvimento de métodos biológicos na luta contra os mosquitos, graças à preocupação crescente com as questões relacionadas ao meio ambiente e a qualidade de vida. Trabalhos de laboratório tem demonstrado a eficácia de diversas protozoários, bactérias, vírus e nematodos, os ensaios de alguns desses agentes tem dado resultados muito promissores. (OMS, 1977). Alguns desses agentes tem demonstrado eficiência também em condições naturais, em ensaios de campo.

Atualmente já se pode constatar em várias situações que a utilização do controle biológico assemelha-se em termos de resultados imediatos aos inseticidas químicos mais eficazes, superando-os no entanto pela pouco possibilidade de selecionar resistentes e preservação de inimigos naturais, o que conduz a uma necessidade de utilização menos freqüente pela menor alteração do ecossistema (NETO E OLIVEIRA, 1985).

\subsection{Fatores Ligados A Interações Entre Populações}

A predação e o parasitismo são exemplos familiares de interações entre duas populações que resultam em efeitos negativos no crescimento e sobrevivência de uma população e um efeito positivo ou benéfico na outra (ODUM, 1988).

\subsubsection{Predação}




\section{- Artrópodes}

A OMS (1984) destaca algumas espécies de mosquitos predadores. Larvas carnívoras de mosquitos do gênero Toxorhynchites alimentam-se principalmente de larvas de outros mosquitos. Algumas espécies desses predador são adequadas para uso em controle biológico. Devido às características ecológicas do gênero, o controle seria viável para mosquitos que habitam criadouros restritos tipo recipiente. A maior dificuldade seria a produção em massa e a liberação dessas larvas nos criadouros (NATAL, 2000).

\section{- Vertebrados}

São principalmente os peixes larvófagos. O uso de peixes como uma opção no MIP irá depender de estudos prévios fundamentados na ecologia que deverão indicar os procedimentos mais adequados a serem adotados ou se vale à pena investir nesses sentido (NATAL, 2000).

\subsubsection{Parasitismo}

\section{- Vírus}

Partindo-se do princípio de que os vírus são parasitas intracelulares obrigatórios poderiam invadir o corpo dos mosquitos, colonizando suas células e as destruindo, levando o indivíduo à morte. Para alguns vírus específicos de mosquitos esses agentes são tidos como de potencial no controle biológico. 


\section{- Protozoários}

Muitos protozoários que são encontrados parasitando vetores na natureza, teriam potencial para controle. Dentre os grupos mais comuns são os microsporídeos, principalmente aqueles pertencentes aos gêneros Amblyospora e Nosema. São parasitas intracelulares o que, sem dúvida complica a produção em massa (NATAL, 2000).

\section{- Fungos}

São representados por fungos aquáticos que invadem larvas de mosquitos. Entre esses, cita-se como que possuindo potencial de uso os gêneros: Coelomomyces, Lagenidium, Culicinomyces, Tolypocladium e Metarhizium (FREDERIC, 1995).

\section{- Vermes}

Segundo, FREDERIC, (1995) os organismos que tem produzido resultados práticos são os nemátodes, destacando-se a espécie Romanomermis culicivorax. As larvas desses nematóides invadem as larvas de mosquitos através da cutícula; sofrem uma muda no interior da larva do mosquito e saem através da cutícula e a larva do mosquito morre. Apresenta a vantagem de poder reciclar nos criadouros provocando controle nas gerações subsequentes de mosquitos. As principais dificuldades são a produção em massa, armazenamento, transporte e aplicação. 


\subsection{Fatores Ligados a Competição Intra-Específica}

\section{- Autocidas}

Trata-se de estratégias de controle pela relação intra-específica. Uma determinada espécie pode ser controlada devido a modificą̧ð̃es genéticas, levando a algum tipo de limitação da prole, ou seja, a espécie alvo torna-se o agente controlador. Tem como base à liberação de mosquitos alterados geneticamente que deverão cruzar com indivíduos tipo selvagem, produzindo uma geração não compatível com o ambiente. Há basicamente dois tipos de autocidas: liberação em massa de individuos estéreis e manipulação genética (NATAL, 2000).

\subsection{Fatores Ligados a Toxinas Ou Princípios Tóxicos}

\section{- Plantas}

O uso de produtos de origem vegetal no controle biológico é uma área de grande potencial, porém pouco conhecida; no que diz respeito à biodiversidade botânica e seu potencial na aplicação no controle biológico. Ganha importância a proteção de habitats naturais ricos em espécies que poderão ser testadas no futuro. Piretrum e Rotenona são produtos extraídos de plantas historicamente utilizados no controle de mosquitos.

\section{- Bactérias}

O controle que pode ser exercido por bactérias foge da modalidade clássica decorrente da competição, parasitismo ou predação. Quando se observa a relação 
bactéria- mosquito, constata-se que a bactéria mata a larva, não pela colonização de seu corpo, mas sim, por ação de proteínas tóxicas. Essas bactérias não causam doença infecciosa nas larvas (WHO, 1984).

As bactérias utilizadas são geralmente encontradas na natureza de forma associada a criadouros de mosquitos. Trata-se de organismos que crescem prontamente em grande variedade de substratos (meio de cultura artificial), tornando-se viável sua produção em massa, sendo essa uma grande vantagem para sua utilização. Há basicamente duas espécies de bactérias que têm sido usadas no controle de mosquitos: Bacillus thruingiensis subsp. Israelensis e Bacillus sphaericus. (NATAL, 2000). 


\section{PREDAÇÃo}

A predação é o primeiro método de controle conhecido e eficaz, se levarmos em consideração a cadeia alimentar, como um equilíbrio natural entre predador e presa. Vários trabalhos sobre essa prática tem demonstrado de forma qualitativa e quantitativa que existem agentes com grande potencial para o uso de forma integrada com os métodos de controle convencionais ou até mesmo como método exclusivo dependendo da situação.

O uso de predadores não é algo novo no controle de larvas de mosquito, mas foi deixado de lado com o uso de defensivos químicos.

\subsection{COPÉPODOS}

Copépodos predadores são um método promissor como controle alternativo em populações larvarias, principalmente em condiçð̃es naturais, pois em laboratório já demonstram bons resultados.

Os copépodos podem ser importantes ao lado de outros métodos de controle no manejo integrado de mosquitos. Tratamentos apenas com copépodos podem a longo prazo controlar algumas espécies de mosquitos, mas o seu uso requer consideraçð̃es e maior conhecimento de seus efeitos sobre o ambiente. Apenas alguns tipos de criadouros são apropriados para a introdução desse tipo de biocontrole, é necessário o uso de 
espécies que adaptem ao criadouro e as suas alterações climáticas entre outros fatores. (MARTEN,1993).

Os copépodos do gênero Mesocyclops são os mais estudados, sendo eficientes contra as principais espécies vetoras. Três espécies tem recebido maior atenção: Macrocyclops albidus, Mesocyclops aspericornis e Mesocyclops longisetus, esta última tem sido apontada como a mais efetiva não só pela sua voracidade de predação, como também pela sua capacidade de sobrevivência na ausência de larvas de mosquito.

MARTEN, 1990 avaliaram seis espécies de copépodos no laboratório e em campo. O copépodo Macrocyclops albidus teve maior ação predatória eliminando todas as espécies de larvas de Aedes, seguido do Mesocyclops longisetus, M. ruttineri, $M$. edax, Acanthocyclops vernalis e Diacyclops navus. A julgar pelo desempenho nesse Macrocyclops albidus e Mesocyclops longisetus podem ser considerados com potencial uso no controle de larvas de mosquitos Aedes sp. em pneus.

MARTEN, 1990 introduziu em duas pilhas de pneus o copépodo Macrocyclops albidus que eliminou 100\% das larvas de Aedes albopictus em 2 meses, durante este período os adultos também desapareceram mas este fato pode estar ligado a diapausa dos mosquitos durante o período de inverno, que se realizou o estudo.

ANDREADIS e GERE, 1992 avaliaram a associação entre 3 espécies de copépodos Mesocyclops venezolanus, M. longisetus e M.aspericornis com larvas do mosquito Anopheles albimanus. Em laboratório as espécies de copépodos predaram larvas de $1^{\mathfrak{Q}}$ estágio, concluindo que copépodos do gênero Mesocyclops podem ser usados no controle de larvas de mosquitos do gênero Anopheles. 
ANDREADIS e GERE, 1992 reportaram o efeito predatório de duas espécies de copépodas Acanthocyclops vernalis e Diacyclops bicucpidatus thomasi contra Aedes canadensis e Aedes stimulans em laboratório. Seus resultados sugerem que onde há uma abundância de outras fontes de alimentos nenhuma das duas espécies de copépodos desempenha seu papel na redução da população larvária.

SCHREIBER e col, 1993 examinaram a capacidade de duas espécies de copépodos Acanthocyclops vernalis e Mesocyclops longisetus para redução de larvas de Aedes albopictus em pneus. A redução da população larvária foi gradual, sendo que em 12 semanas A.vernais desapareceu. Em 18 semanas a redução nos tratamentos com $M$. longisetus foi de $50 \%$, demonstrando ser eficaz até mesmo durante o inverno.

TIETZE e col, 1994 avaliaram os efeitos da integração d Mesocyclops longisetus, com três agentes "bioracionais" Bacillus thurigiensis var. israelensis (B.t.i.), Bacillus sphaericus (B.s.) e o methoprene (regulador de crescimento). Este estudo determinou que o copépodo é compatível com B.t.i. e B.s. e methoprene nas concentraçð̃es determinadas para o controle do mosquito.

SANTOS, ANDRADE E CARVALHO, 1996 utilizaram copépodo Mesoclyclops longisetus no controle de larvas de Aedes albopictus em armadilhas no campus da UNICAMP e obtiveram resultados de até $99,2 \%$ de redução nessa população. Os autores sugerem a aplicação do método para ambientes limitados como: parques, condomínios, escolas, cemitérios, etc.

SCHREIBER e col, 1996, observaram os efeitos do Mesocyclops longisetus em mosquitos que habitavam pneus verificando a influência dessa espécie nesse tipo de criadouro. Obtiveram um predomínio de Aedes albopictus (88\%) em seguida Culex 
quinquefasciatus, Culex salinarius e Anopheles crucians. Afirmam que $M$. longisetus introduzidos em pneus reduzem as larvas de mosquitos durante a maior parte do ano.

RAWLINS e col, 1997 avaliaram em laboratório o consumo larval de copépodos e sua integração aos programas de controle que utilizam o controle químico com Temephos. Quanto à capacidade predatória os mais representativos foram os gêneros Macrocyclops e Mesocyclops contra larvas de mosquitos Aedes sp e Culex sp, demonstrando que há espécies de copépodos capazes de sozinhos ou associados a inseticidas organofosforados controlar larvas de Aedes aegypti, pois são tolerantes a dosagens de inseticidas normalmente tóxicas para os mosquitos.

SCHAPER e col,1998 em experimentos de laboratório demonstraram que o copépodo Mesocyclops thermocyclopoides é capaz de eliminar 7 larvas de Aedes aegypti por dia. Nestas condiçðes M.thermocyclopoides é uma espécie predadora para larvas de Ae. Aegypti podendo ser usado satisfatoriamente como controle biológico.

ESCALANTE e col, 1998 em trabalho de campo determinaram a efetiva reduçăo de Aedes aegypti por Mesocyclops longisetus em caixas d'água, pneus e vasos de cemitérios. A redução foi de $37,5 \%$ em caixas, $67,5 \%$ em vasos e $40,9 \%$ em pneus, demonstrando dificuldades no uso de copépodos para pneus e caixas por serem locais onde há maior exposição ao clima reduzindo a sobrevivência.

MARTEN e col, 2000 investigaram a interação ecológica de 3 espécies de copépodos Macrocyclops albidus, Acanthocyclops vernalis e Megacyclops latipes contra Culex quinquefasciatus em água poluída. Em condiçðes de laboratório as espécies mataram um número substancial de larvas, porém em condições de campo a poluição 
não só cria mas também estoca bactérias que alimentam as larvas como também excluem seus predadores naturais, dificultando o controle.

\subsection{PEIXES}

Os peixes tem uma pequena, mas importante parcela no programas de controle de mosquitos. Os programas incluem a compreensão da biologia dos peixes adultos e monitoramento de suas larvas, o uso de larvicidas em um programa integrado com métodos químicos e biológicos, como um reforço contra as espécies vetoras (BOKLUND, 1997).

Várias agências de saúde tem reconhecido que os peixes larvívoros são importantes como agentes no biocontrole de mosquitos (NELSON e KEENAN, 1992).

$\mathrm{Na}$ Califórnia, alguns estudos demonstraram que os peixes são altamente efetivos no controle no número de larvas de alguns criadouros e moderadamente efetivos ou ineficientes em outros. O uso mais importante de peixes é em criadouros semipermanentes.

A espécies mais estudada é Gambusia affinis, conhecido como "mosquitofish", nativo das Américas do Norte e Central, a sua eficiência como agente de controle depende de fatores como: abundância de vegetação, relativa abundância de presas, número de predadores e fatores bióticos que afetam sua reprodução como a fecundidade e a sazonalidade dos criadouros (OFFILL e WLATON, 1999). Em lugares com água 
com alto teor de resíduos e intensa contaminação que impedem que outras espécies de peixes possam viver e exercer um controle efetivo, a espécie mais promissora é Poecilia reticulata.

Um dos problemas relacionados à utilização de peixes é a sua baixa fecundidade, dificultando sua produção em massa em campo.

MULLIGAN e col, 1983 investigaram eficiência predatória e a sobrevivência potencial de Gambusia affinis, por 14 semanas durante o verão. Esta espécie foi efetiva reduzindo o numero da população de adultos de Culex quinquefasciatus. Na região tratada houve redução de 75,89 e $94 \%$ nas áreas com peixe. Esta espécies de peixe sobrevive em condiçð̃es de "esgoto" e efetivamente suprimiu a produção de mosquitos. Se usada em lugares fechados em áreas de produção continua de água contaminada, pode ser um importante componente nos programas integrados em determinados criadouros.

TODD e GIGLIOLI, 1983 monitoraram por 3 anos o numero de Gambusia puncticulada e outro peixe fluvial, assim como a ocorrência de Aedes taeniorhynchus. Os peixes fluviais foram incapazes de controlar os mosquitos, devido aos efeitos da inundação: 1) mediata incubação dos ovos; 2) diluição da população de peixes e 3) demorado aumento do numero de G.puncticulada e a falta de aumento entre outras espécies peixes.

VARGAS e VARGAS, 1985 avaliaram em laboratório a ação predadora do peixe Priapichthys annectens sobre as larvas de culicídeos. Ao examinar o conteúdo intestinal desses peixes observaram uma baixa população de insetos. Seus resultados foram influenciados por fatores externos como volume da água, cor do recipiente, quantidade 
de oxigênio e erros de manejo. As larvas mais ativas foram predadas mais rapidamente. Em condiçães naturais a eficiência do peixe foi maior, sendo assim em seu habitat natural pode servir como um controle adequado de larvas de culicídeos.

MIAN e col, 1986 utilizaram a associação de três agentes de biocontrole o copépodo Mesocyclops leuckarti pilosa e duas espécies de peixes Cyprinodon macularis e Poecilia reticulata e avaliaram seu potencial predatório sobre larvas de mosquitos Aedes aegypti em condições de laboratório com água de esgoto. O copépodo não foi afetado pelas condições da água de esgoto, o que não alterou sua ação predatória. No entanto, esses peixes demonstraram um potencial de controle, já que apresentaram boa sobrevivência e crescimento populacional em água de esgoto durante os meses de atividade do mosquito, as alteraçðes climáticas durante os meses de inverno podem alteram a sobrevivência dessas espécies por isso recomendam ser mais bem avaliadas, assim como o aumento da poluição.

CECH, jr e LINDEN, 1987 compararam a habilidade dos peixes Orthodon microlepidotus e Gambusia affinis contra larvas de mosquitos. Os resultados mostraram que O.microlepidotus apresentou menor predação, concluindo que o peixe G.affinis é mais eficaz, apesar da densidade larvária poder ter afetado esse resultado. Houve também uma diminuição no número de larvas do grupo controle que pode ser atribuído a predadores invertebrados, alterando assim sua comparaçăo com o grupo tratado com O.microlepdotus.

HOLCK e MEEK, 1987 avaliaram a toxicidade e selecionaram inseticidas sobre o peixe Procambarus clarkii e três espécies de mosquitos Anopheles quadrimaculatus, Culex salinarius e Psorophora columbiae. Demonstrando que os 
inseticidas são tóxicos para o peixe, já os bioagentes de controle Bacillus sphaericus e. Bacillus thuringiensis var. israelensis, não demonstraram ser tóxicos para essa espécie de peixe.

KRAMER e col, 1987 avaliaram o impacto do peixe Gambusia affinis sobre a densidade larvaria de Culex tarsalis, Anopheles freeborni e. Anopheles franciscanus, não havendo diferença significante entre o grupo controle e o tratamento essa espécie de peixes.

FONSECA e col, 1988 testaram a efetividade biorreguladora do peixe Poecillia reticulata em condiçðes de laboratório, quanto à preferência alimentar entre os estágios larvais II e III dos mosquitos Aedes aegypti e Culex quinquefasciatus. Avaliaram ainda sua capacidade predadora em função do sexo, tamanho, presença e ausência de vegetação. Os autores mostraram um maior consumo de larvas diárias pelos peixes maiores tanto em machos como em fêmeas. Todos os experimentos apresentaram um maior consumo de larvas de Ae. Aegypti, e na presenças de vegetação.

LINDEN e CECH jr, 1990 investigaram os efeitos da vegetação e a presença de presas alternativas a ação predatória de Gambusia affinis sobre imaturos de Culex tarsalis. Mesmo na presença de vegetação, as larvas do mosquito foram consumidas em grande número demonstrando uma seleção no consumo de presas. Os autores demonstraram também que a presenças de outras presas mais acessíveis pode diminuir a predação das larvas de mosquito, mas não elimina-la totalmente.

AVILA e col, 1991 obtiveram resultados satisfatórios quando em condições naturais introduziram o peixe Poecilia reticulata em 4 reservatórios de água contaminada, avaliando a capacidade biorreguladora sobre larvas de Culex 
quinquefasciatus. Essa espécie pode viver com êxito nesses reservatórios, apresentando tanto em laboratório como em campo uma grande voracidade por larvas de todos os estágios e pupas demonstrando que podem constituir uma arma poderosa na luta contra os mosquitos.

LOUNIBOS e col, 1992 descreveram peixes nativos do sul da Flórida predadores de larvas de mosquitos Mansonia sp. Em experimentos, em tanques e pequenos reservatórios demonstraram que o peixe Gambusia holbrooki reduz as densidades de larvas de mosquitos.

NELSON e KEENAN, 1992 compararam a eficiência de duas espécies de Fundulus zebrinus e Gambusia affinis, e sua associação em testes de campo, demonstrando que associados controlam as larvas, ressaltando as vantagens de que peixes não geram resistência.

RAWLINS e col, 1993 investigaram o consumo de larvas de Aedes aegypti por Poecilia reticulata em pequenos containers em laboratório e em tambores no campo. Observando que o consumo médio do adulto é de 100-400 larvas/dia, já o imaturo 90140 larvas/dia em condições artificiais. Em condiçð̃es naturais esse consumo foi de 550 larvas/dia para o adulto e 113 larvas/dia para o imaturo. A habilidade desse peixe em sobreviver e prosperar em criadouros expostos diretamente a luz solar, elevadas temperaturas e alteraçð̃es mecânicas diárias, o fazem um bom agente para o controle de populaçð̃es larvarias.

OFFLL e WALTON, 1999 compararam os peixes Gasterosteus aculeatus e Gambusia affinis como agentes de controle. G. aculeatus foi menos efetivo que $G$. affinis na redução de populaçð̃es de mosquitos imaturos. Juntas as duas espécies não 
foram eficientes no controle. Em condiçð̃es naturais não foram representativas,quanto a sua ação de controle, necessitando de maior investigação para obter resultados mais conclusivos.

\subsection{OUTROS INVERTEBRADOS}

Vários filos de invertebrados tem recebido atenção, quanto a seu papel de inimigos naturais de larvas de diversas espécies de mosquitos.

Artrópodes predadores tem recebido muito interesse em seu papel de inimigos naturais de imaturos de mosquitos, mas raramente tem progresso como agentes de controle biológico (COLLINS e WASHINO, 1985 in TIETEZE e MULLA,1991).

Em contraste com a maioria dos insetos predadores, o camarão produz ovos resistentes a dissecação, uma adaptação ecológica para corpos temporários de água. (TIETZE e MULLA, 1990). Isso pode facilitar sua aplicação.

Uma promissora ferramenta nos programas manejo integrado é o uso de planarias, por serem eficientes predadores de larvas de mosquitos. Possuem alta produção, fácil manutenção e dispersão em campo. Possuem alta tolerância para pesticidas incluindo reguladores de crescimento e Bacillus thurigiensis var. israelensis (B.t.i) (MELLO e ANDRADE, 2001).

A classe de insetos mais distintos habitantes da superficie da água dos criadouros são os hemípteras. Eles são pequenos e de fácil percepção. O gênero Microvelia tem sido conhecido por predar uma variedade de pequenos organismos em seu habitat, 
demonstrando que também as larvas de mosquitos podem ser suas presas (MIURA e TAKAHASHI, 1988).

Algumas espécies do mosquito Toxorhynchites tem suas larvas avaliadas quanto à ação predatória e seu canibalismo. Essa ação canibal é caracterizada por matar a presa, mas não consumi-la.

LACEY e DAME, 1982 determinaram em laboratório o efeito do Bacillus thurigiensis var. israelensis sobre larvas de Toxorhynchites rutilus, na presença e ausência de presas. A mortalidade chegou a $98 \%$, dez dias após a exposição na maior concentração do larvicida. Pesquisas adicionais permitirão avaliara melhor os efeitos dessa bactéria sobre esse gênero de mosquito em condições de campo, uma vez que sejam avaliados já que se tratam de candidatos ao controle integrado de mosquitos.

FOCKS e col, 1983 Toxorhynchites rutilus uma espécie de mosquitos predador de larvas em habitats naturais e artificiais como pneus descartados e buracos de arvores. Após a liberação em área urbana a oviposição desse predador foi observada em criadouros de Aedes aegypti. A preferência desta espécie silvestre por buracos de arvores para oviposição reduz a habilidade para criadouros artificiais e conseqüentemente seu sucesso para controle urbano de criadouros de mosquitos.

GEORGE e col, 1983 realizaram testes de laboratório com planarias avaliando seu potencial de controle em mosquitos, obtiveram resultados significantes com redução de até $81 \%$ em larvas de Culex $s p$., sendo a redução media de $74 \%$. A emergência dos adultos foi reduzida em media 80.89 e $88 \%$ de acordo com a quantidade de planarias colocadas em cada tratamento. 
ALI e MULLA, 1983 a eficiência predatória da planaria Dugesia dorotocephala, contra populaçð̃es de mosquitos foi avaliada durante os verões de 1975,1976 e 1977. a redução máxima a cada verão foi de $52,3,58,3$ e $73 \%$ respectivamente. As planarias introduzidas nos criadouros persistiram em toda à parte em cada período avaliado, e demonstraram fraco aumento populacional, mas este aumento foi inconsistente e não proporcional à densidade inicial da inoculação.

CASTNER e BAILEY, 1984 os níveis de predação foram testados em laboratório para determinar os efeitos imediatos a longo prazo das larvas Toxorhynchites amboinensis sobre populações de Aedes aegypti, não havendo uma significante redução na emergência dos adultos em até 2 semanas após a introdução do predador. Os níveis de controle obtidos na $2^{\circ}$ e $3^{\circ}$ semana após a introdução foi proporcional ao numero de larvas predadoras originalmente introduzidas. A adição de um predador por semana teve um melhor controle durante a $4^{\circ}$ semana após a introdução do predador. CÔNSOLI e col, 1984 avaliaram a atividade predatória, em laboratório, de Heobdella triserialis lineata (Hemiptera: Belostomatidae) sobre ovos, larvas e pupas de Aedes fluviatilis e Culex quinquefasciatus. Foi observada apenas predação de larvas e pupas. Houve uma menor oviposição das fêmeas de C.quinquefasciatus em recipientes que continham os hirudíneos.

MIJARES e BROCHE, 1985 avaliaram tanto em laboratório como em condiçð̃es naturais coleópteros aquáticos (Dytiscidae $s p$, hydrophilidae $s p, D$. longimanus) sobre larvas de Culex quinquefasciatus estimaram quantitativamente os efeitos da predação sobre a redução e regulação do número de larvas de mosquito. Tanto no laboratório como em campo observou-se redução na população de larvas como os coleópteros , 
porém esta redução está diretamente ligada a densidade dos predadores, não desconsiderando a possibilidade de utilização no controle.

RUSSO, 1986 comparou a ação predadora de larvas de 5 espécies de Toxorhynchites sobre larvas de outras espécies de mosquitos. Observando que a predação está diretamente relacionada com a densidade de presas. A diferença entre a intensidade de larvas mortas entre as espécies testadas pode estar relacionada com a densidade de presas e a competição por comida.

MIURA e TAKAHASHI, 1988 determinaram a ação predatória das ninfas do inseto aquático Enallagma civile sobre larvas de Culex tarsalis, demonstrando que os últimos estágios de $E$. civile são capazes de predar larvas de $3^{\circ}$ estágio da espécie alvo predando 6,06 larvas/dia. Houve uma correlação positiva entre a densidade e o consumo de presas, porém quando houve um grande aumento no numero de predadores essa relação passou a ser inversa entre a densidade do predador e o consumo de presas, ou seja quanto maior a densidade de predador menor será seu consumo, que interferiu diretamente em sua capacidade de controle.

MIURA e TAKAHASHI, 1988 introduziram 2 machos e 2 fêmeas adultos do hemíptera Microvelia pulchella em recipientes com 2 litros de água contendo larvas de mosquitos, demonstrando que $M$. pulchella não só é capaz de predar, mas também sobrevive e pode reproduzir em criadouros de mosquitos tendo as larvas de mosquitos como alimento.

SHERRATT e TIKASINGH, 1989 investigaram em laboratório a predação de Aedes aegypti por Toxorhynchites moctezuma e observaram que as larvas de $2^{9}$ e $4^{q}$ 
estágio de T.moctezuma consomem larvas mais jovens, quando cada estágio foi oferecido isoladamente. Indicando ser um promissor agente de biocontrole.

CONSOLI e col, 1989 avaliaram em laboratório a ação predatória de ninfas de $1^{\circ}$ a $5^{\circ}$ estágios e adultos do hemiptera aquático Belostoma micantulum sobre larvas de 4 estágio e pupas de Aedes fluviatilis na presença e ausência de um pequeno molusco Biomphalaria glabrata. Observaram que as larvas de $5^{\circ}$ estágio demonstraram maior predação sobre larvas e pupas de mosquitos não tendo interferência do molusco citado, indicando que a presença de oura presa não altera sua ação predatória. Em seguida observou-se a predação do adulto na ausência do molusco. Os estágios mais jovens tiveram uma menor predação, recomendam um maior estudo sobre a biologia do hemiptera e testes de campo.

TIETZE e MULLA, 1990 investigaram o efeito do camarão Triops longicaudatus, que produziu uma significante redução na população de imaturos e adultos estocados do mosquito Culex tarsalis.

TIETZE e MULLA, 1991 em estudos de laboratório e campo descreveram os efeitos do camarão Triops longicaudatus na oviposição e no desenvolvimento de mosquitos imaturos Culex sp. Observaram que a agitação da água com o camarão diminui a oviposição das fêmeas de Culex quinquefasciatus. Quando comparados ao controle, os testes de campo com camarão tiveram mais que $95 \%$ de controle de larvas de quarto estágio e pupas em 10 dias. Naturalmente a alta fecundidade junto à resistência ao calor dos ovos fizeram do camarão um atraente agente de controle em águas quentes. Sugerem uma maior investigação de técnicas de produção em massa, coleta, aplicação para validar esse potencial agente de controle. 
LEE e col, 1994 em cinco experimentos de laboratório para determinar se a formiga Solenopsis invicta preda ovos do mosquito Psorophora comlumbiae e se essa predação é efetiva nos estágios embrionários, e se ocorre alguma alteração na oviposição do mosquito em diferentes tipos de substratos com diferentes temperaturas. Essas formigas comem os ovos dos mosquitos. Eles concluíram que a formiga $S$. invicta é potencialmente um predador de ovos $P$. comlumbiae. A temperatura é provavelmente o fator mais importante na ação predadora da formiga.

MELO e ANDRADE, 2001 observaram a predação da planaria Dugesia tigrina sobre larvas de Aedes albopictus e Culex quinquefasciatus. A planaria mostrou-se eficiente sobre larvas $1^{\circ}, 2^{\circ}$ e $3^{\circ}$ a predação foi mais intensa durante 1-4 dias, Culex quinquefasciatus foi mais rapidamente predado que Ae. aegypti que reagiu a planaria, resultando em maior sucesso em escapar do ataque do predador. 


\section{PARASITISMO}

A ação parasitaria pode ser comparada aos inseticidas reguladores de crescimento, já que impedem que a larva complete seu desenvolvimento.

O controle microbiano não é substituto do controle químico, mas o que se pode afirmar é que ambos podem conviver simultaneamente; nesta tentativa, alguns conceitos do manejo da praga têm sido tentados, mas sua utilizaçåo ainda deixa muito a desejar. $\mathrm{O}$ que podemos evidenciar é que muitas vezes a habilidade patogênica em condiçð̃es de laboratório é suplementada pela habilidade de sobrevivência às condiçð̃es do meio ambiente (MESSIAS, 1989).

Uma das áreas de investigação de agente de controle de mosquitos envolvem a inoculação de micróbios para alcançar extensivos períodos de controle. Existem grupos importantes de organismos para esta finalidade como: nematóides, microsporídia e fungo (BECNEL, 1992).

\subsection{NEMATODOS}

Os nematodos (Nematoda: Mermithidae) são indicados como promissores agentes de controle de biológico de mosquitos, pois são endoparasitos obrigatórios que completam seu desenvolvimento no interior de seus hospedeiros que podem ser larvas de mosquitos (Diptera: Culicidae) (MIJARES e col, 2000). No seu estado infectivo préparasita o nematodo deve encontrar um hospedeiro adequado entre 72 a 96 horas após a eclosão dos ovos. O parasita penetra na larva perfurando sua cutícula com seu estilete. 
Depois de 5-6 dias de desenvolvimento emergem as formas posparasitas, que matam as larvas hospedeiras em $4^{\varrho}$ estágio de desenvolvimento. As formas posparasitas necessitam de um substrato úmido para mudar e reproduzir (MIJARES e BELLINI, 2000). Algumas espécies de nematodas diferem quanto a completar o desenvolvimento em larvas ou estágio adulto de seus hospedeiros (BLACKMORE e col, 1993).

Algumas espécies de nematodas tem demonstrando ser eficazes no controle de larvas de mosquitos em condiçð̃es de laboratório e campo, demonstrando serem capazes de reduzir as altas densidades de larvas de mosquitos dos gêneros Anopheles, Aedes e Culex em condições de campo (MIJARES e BELLINI, 2000).

As espécies mais estuda são Romanomermis culicivorax e $R$ iyengari avaliadas com alternativas para os programas de controle químico, tem incluído estudos de fatores que afetam a estabilidade e eficácia desses agentes em diferentes habitats. Entre esses fatores estão água, temperatura e química, abundância de predadores invertebrados, aplicação de herbicidas e pesticidas (MIJARES e PACHECO, 1997).

Alguns estudos foram feitos para elucidar a biologia dos nematodas, mas relativamente pequenos esforços têm sido feito para examinar a dinâmica das interaçðes entre nematodas e seus hospedeiros em populaçðes naturais (BLACKMORE e NIELSEN, 1990).

NAYAR e col.,1984 testaram a suscetibilidade de mosquitos, ao nematoda Brugia patei, descrito comumente no sistema linfático de cães e gatos, demonstrando que esse parasita se desenvolveu em larvas de Aedes aegypti, suportando o desenvolvimento de alguns nematodas desse gênero. 
WALKER e col., 1985 avaliaram o uso do Romanomermis culivorax como componente do Manejo Integrado de Psorophora columbiae como espécie alvo. A porcentagem de parasitismo após um período de 22 meses variou ate $54,1 \%$. O parasita não demonstrou poder ser usado como um meio único de controle, nas condiç̃̃es de estudo, pois a infeç̧ão maior de $54 \%$, obtida nesse estudo não e aceitável em programas de controle, como única técnica. De qualquer modo o controle integrado dever ser implementado incluindo produtos químicos, agentes de biocontrole e estratégias de manejo da água para aumentar o sucesso do controle.

MIDDAUGH e col., 1985 a eficácia de jovens Menidia beryllina, de 20-22 e 3133 dias de idade para o controle de larvas de mosquitos foi determinado em laboratório com larvas de $1^{\circ}$ e $2^{\circ}$ estagio de Aedes taeniorhynchus. Os tratamentos de campo determinaram a eficácia sobre Culex quinquefasciatus. Além de demonstrar ser uma promissora medida de controle para larvas de mosquitos, seu crescimento observado em habitats de água salgada e sua alta capacidade reprodução sugerem M.beryllina tem potencial equivalente a de um peixe carnívoro.

WALKER e col., 1987 em laboratório testaram o potencial de regulação de Ascogregaria barreti como parasita de Aedes triseatus, observaram que apesar de severamente infectadas, as fềmeas de mosquito prolongaram seu tempo de desenvolvimento quando comparado as não infectadas. Em condi̧̧ð̌es de campo a infecção não afetou a emergência, tempo de desenvolvimento ou o tamanho do mosquito, levando a concluírem que este parasita não tem potencial como agente de controle dessa espécie de mosquito. 
REARDON e LUNT, 1989 capturaram mosquitos 1736 mosquitos de 11 espécies, para investigar a possibilidade de parasitismo por nematodas. Observaram a presença de nematodas parasitas em 13 Aedes vexans, indicando uma possibilidade para o controle.

BLACKMORE e NIELSEN, 1990 coletaram larvas de Aedes sp. infectadas por Romanomermis sp .Aedes nevadensis, Ae.impiger, Ae.pullatus e. Ae. Punctor foram as espécies hospedeiras predominantes. O parasitismo foi de 55 a $93 \%$ havendo diferença significante entre os locais de coleta.

KENNY e RUBER, 1991 examinaram 792 larvas e 12.400 adultos do mosquito Coquillettidia perturbans em relação a infecção por nematodas. Não foi verificado nos adultos, nem em larvas essa infeç̧ão, apenas em 3 larvas coletadas entre os meses de setembro e outubro, segundo a Segunda ocorrência natural reportada nessa espécie de mosquito.

BLACKMORE e col., 1993 observaram a ocorrência de parasitas em 11 espécies de mosquitos. Os hospedeiros naturais de nermetideos (Nematoda: Mermithidae) incluem Aedes vexans, Ae.canadensis, Ae.cinereus, Ae.diantaeus, Ae.punctor, Anopheles punctipennis e Coquillettidia perturbans e larvas de Ae.abserratus, Ae.canadensis, Ae.cinereus, Ae.commumis, Ae.diantaeus, Ae.provocans, Ae.punctor, Ae.stimulans e Cq.perturbans.

GARCIA e BECNEL, 1994 infectaram com gregarina Ascogregaria taiwanensis oito espécies de larvas de mosquitos testadas em laboratório, havendo uma prevalência natural de $68-100 \%$, durante o experimento. O parasita não completa seu ciclo de vida no Aedes aegypti. As diferenças entre o parsitismo podem estar relacionadas a área de 
estudo. Houve uma maior infectividade no inverno, pois no verão há uma redução na viabilidade desse parasita com o aumento da temperatura. Baseado nesse estudo concluem que o parasita teve um pequeno impacto na mortalidade nas condições testadas, em outras condições podem diferir em patogenicidade e especificidade em seu hospedeiro.

MIJARES e col., 1996 determinaram a suscetibilidade dos diferentes estágios larvais e o nível de controle de Aedes taeniorhynchus pela forma pré-parasita Romanomermis iyengari, que se mostrou eficiente, porém a salinidade pode afetar essa ação em condiçð̃es naturais. A maior taxa de parasitismo ocorreu no $1^{\circledR}$ e $2^{0}$ estágios 100 $97 \%$ e do $3^{\circ}$ ao $5^{\circ}$ foi maior que $90 \%$. Houve redução até 8 dias após o tratamento.

MIJARES e PACHECO, 1997 estabeleceram a redução da população de larvas de mosquitos em laboratório pelo nematoda Romanomermis culivovorax em água de esgoto. Os anofelinos foram os mais suscetíveis ao parasitismo que os culicíneos. Os resultados, bem como a forte propensão para estabilidade natural e reciclagem dessa espécie de nematodo, indicaram ser um promissor agente de controle biológico contra imaturos de mosquitos em seus criadouros.

PACHECO e col., 1998 realizaram um estudo com larvas de Anopheles pseudopunctipennis, em condições de laboratório e campo para avaliar os níveis de suscetibilidade ao parasitismo pelo nematodo Romanomermis iyengari, os resultados foram similares para os dois testes com elevados niveis de infecção com valores 90 100\% em laboratório e $85-95 \%$ no campo. Observaram redução das densidades larvárias 7 dias após a aplicação, demonstrando uma elevada suscetibilidade desta espécie de anofelino ao parasitismo por nematodas. 
MIJARES e BELLINI, 2000 em laboratório e em campo, aplicaram o nematoda Romanomermis iyengari, os resultados nas duas condições foram similares indicandio uma maior suscetibilidade ao parasitismo das larvas I a III, que pode ser devido ao menor espessura da cutícula- quitina. As taxas de parasitismo alcançaram $100 \%$. Sua ação foi comparada aos inseticidas químicos como os hormônios inibidores de crescimento ou de síntese de quitina, demonstrou-se inofensivo aos demais habitantes do criadouro.

MIJARES e col., 2000 avaliaram o parasitismo pelo nematoda Romanomermis culicivorax em laboratório e em campo, obtendo resultados similares, nas duas condições, havendo um maior parasitismo das larvas mais jovens, e quanto maior a proporção de parasitas maior a infectividade. Observaram também o parasitismo de pupas e que o desenvolvimento desse parasita pode prolongar-se pela vida adulta do mosquito. Apresentaram resultados satisfatórios, chegando em alguns testes a eficácia de $100 \%$, porém maiores estudos devem ser realizados antes que se recomende a aplicação. 


\subsection{MICROSPORIDIO}

Microsporidia são alguns dos mais comuns patógenos de mosquitos,sendo um agente de controle biológico manipulável.

UNDEEEN e DAME, 1987 reportaram o efeito de Vararia culicis e Nosema algarae sobre Anopheles quadrimaculatus e Culex quinquefasciatus. A mortalidade das larvas foi maior em reservatórios naturais que em laboratório. Os testes demonstraram que houve mortalidade associada ao método utilizado, de eliminação e estimativa da população, assim os resultados de laboratório podem ter sido influenciados pela metodologia.

ANDREADIS, 1989 utilizou a infecção com Amblyospora connecticus e liberados pelo hospedeiro intermediário o copépodo Acanthocyclops vernalis em tambores de água, demonstrando uma relação positiva entre em populações de Aedes cantator. Concluem que este estudo representa um progresso rumo a efetiva utilização de parasitas microspodirios de ocorrência natural, ajudar a suprimir mosquitos hospedeiros. Copépodos infectados podem ser usados para infectar populações de mosquitos suscetiveis, sendo necessário maiores estudos sobre o emprego especifico. 


\subsection{FUNGOS}

A utilização de fungos para o controle de insetos está fundamentada na capacidade que esses têm de infectar os insetos e lhes causar doença e morte, num processo que dependente de fatores bióticos e abióticos, descritos pela primeira vez em 1835, por Agostinho Bassi; que teve sua utilização proposta como controladores alternativos de pragas em 1879 por Metchnikoff (MESSIAS, 1989).

Os fungos penetram direto na cutícula da larva, onde uma sequência de eventos de desenvolvimento produz esporângios e matam o hospedeiro completando o ciclo (BECNELL,1992). A morte da larva ocorre porque o fungo rouba seus nutrientes, esse fungo é capaz de se reciclar (HORBY e col., 1992).

Por possuírem hospedeiros específicos, as larvas, os fungos tem atributos para serem considerados agentes de controle, podem ser produzidos comercialmente, tem bom ciclo vital e pode ser aplicado por métodos e equipamentos usados para larvicidas químicos líquidos (HORBY, e col., 1992).

Para o desenvolvimento dos como biorreguladores são necessários estudos de ordem genética, produção em larga escala, formulą̧ð̃es, bioensaios, avaliaçð̃es de campo como dosagem, épocas de aplicações, que devem ser conduzidas num esforço conjunto de entomologistas, microbiologistas, geneticistas, bioestatísticos, fitopatologistas e outros pesquisadores (MESSIAS, 1989).

Para que os métodos de melhoramento genético possam ser utilizados, há necessidade de um amplo conhecimento da biologia dos fungos a serem melhorados, 
essencialmente dos processos de recombinação que ocorrem nesses fungos. Além da utilização da variabilidade natural já existente na espécie, e do isolamento de mutantes espontâneos ou induzidos, o perfeito conhecimento dos sistemas de recombinação existentes é requisito essencial para que o melhoramento genético possa ser aplicado (AZEVEDO, 1989).

Uma das espécies mais estudadas é o Lagenidium giganteum, que tem demonstrado eficácia suficiente em alguns estudos que lhe garante consideração como uma alternativa para o controle quimico de larvas. $O$ interesse nesses fungos esta na habilidade de persistirem a rigorosos invernos com variações no meio ambiente, incluindo variações na densidade de mosquitos hospedeiros (GUZMAN e AXTELL, 1987).

JARONSKI e AXTELL, 1982 determinaram a eficácia de Lagenidium giganteus em águas organicamente poluídas usando uma escala piloto, para identificar componentes específicos da poluição orgânica que limitam a transmissão do fungo, para desenvolver um modelo de efeito sobre a população eficiente contra larvas de Culex quinquefasciatus. Este fungo é efetivo em criadouros poluídos com matéria orgânica.

JARONSKI e AXTELL, 1983 introduziram isolados do fungo Lagenidium giganteum em criadouros naturais, semipermanentes e observaram a persistência do fungo e a infecção da larva durante o periodo de flutuação. Nos bioensaios houve $93 \%$ de infecção larval em água deionizada e $92 \%$ em água comum. Demonstraram que o fungo pode reciclar -se sendo bom agente de biocontrole, porém é necessário à promoção de estudos, após a aplicação artificial em condições variadas, para determinar se a persistência em longos períodos promoverá o controle de mosquitos. 
KERWIN e WASHINO , 1986 testaram 2 métodos de aplicação em campo de culturas de fermentação nos estágios sexual e assexual de Lagenidium giganteum para o controle de mosquitos. A aplicação do estágio assexual resultou em altos níveis de controle imediato das larvas de Culex tarsalis e Anopheles freeborni. Devido a isso os autores indicam a possibilidade de uma ação conjunta com outros métodos de controle.

GUZMAN e AXTELL, 1987 determinaram experimentalmente os efeitos da inoculação de Lagenidium giganteum em água estagnada em populações de mosquitos imaturos Culex quinquefasciatus. O número de adultos emergidos durante 138 dias foi de $82 \%$ de redução nos criadouros tratados, durante as ultimas semanas de tratamento foi maior que $90 \%$. A qualidade da água pode alterar os resultados. Uma baixa aplicação de L.giganteum em condiçð̃es ambientais apropriadas pode ser uma alternativa quando diminuir a atividade de patógenos, levando a redução da população de larvas e aumentando o nível de patógenos no habitat.

AXTELL e GUZMAN, 1987 em laboratório testaram formulaçð̃es de encapsulados nas fases sexual e assexual para infectividade do fungo em Culex quinquefasciatus. Sua produção é relativamente simples mas o tamanho das capsulas e o número de pré esporângios por cápsulas variou entre as porções. Em campo as larvas foram infectadas, ocorrendo uma gradual diminuição na densidade de larvas 2-7 dias após o tratamento. No tratamento de campo, não houve o efeito dose-mortalidade de larvas, mesmo com alto número de capsulas utilizadas. As variaçðes nas condiçðes naturais alteram o efeito obtido em laboratório. Estes experimentos demonstraram o habilidade do fungo no processo de encapsulação e a viabilidade persistente, em várias 
formulações, porém maiores estudos devem ser realizados em relação ao preparo e as técnicas de estocagem para o seu uso.

GOETTEL, 1987 aplicou em criadouros semi-permanentes e temporários, o fungo Tolypocladium cylindrosporum avaliando como agente microbiano de controle de mosquitos. Cinco espécies de mosquitos foram infectadas. A razão de infecção foi maior que $33 \%$ para os blastoconidia e $55 \%$ para conidia. Isto especula que os mosquitos coletados em campo sucumbem ao fungo como resultado para o estress de transferencia para as condições de laboratório. Isto demonstra que não impede seu potencial como agente de controle microbiano.

GOETTEL, 1987 usou larvas de Aedes aegypti, Aedes vexans e Culiseta inormata para estudar a patogenicidade do fungos Tolypocladium cylimdrosportum em cinco concentrações diferentes. Houve uma correlação entre a dosagem e a patogenicidade, as 3 espécies de mosquitos foram suscetíveis ao fungo em todas as temperaturas testadas, a média de tempo foi entre 3 e 14 dias, tendo sua virulência diminuída requerendo doses maciças, melhorar as para respostas. Concluiu que o método utilizado foi inadequado ao fungo testado necessitando de melhoramentos, para resultados mais conclusivos.

KERWIN e WASHINO, 1987 aplicaram o fungo parasita facultativo Lagenidium giganteum em larvas de mosquito em campos de arroz. As aplicaçðes iniciais indicaram que 30 litros de fermentação d cerveja por hectare foi suficiente para o controle de Culex tarsalis. A maior aplicação resultou em $40 \%$ de infecção confirmada de Culex tarsalis e Anopheles freeborni, com o aumento da aplicação resultou em $90 / 5$ de mortalidade inicial de C.tarsalis e Afreeborni e $65 \%$ Aedes melanimon. Testes de campo 
descreveram a viabilidade do uso de fermentação do estágio assexual desse fungo. A desvantagem do uso desse estágio do ciclo de vida do fungo é a inabilidade de resistir a dissecação ou abrasão e relativamente pequena estabilidade em estocar 2 a 8 semanas dependendo da produção e protocolos de estocagem. Todos os fatores como manutenção, cultura e estoque afetam a capacidade de esporulaçăo do fungo e sua patogenicidade para as larvas. Cuidados e controle desses fatores citados otimizam a rotina de uso desses fungos.

WASHBURN e col., 1988 descobriram que a interação entre o protozoário parasita Lambornella clarki (Ciliophora:Tetrahymenidae) e o fungo parasita oportunista Pythium flevoense podem reduzir substancialmente o tamanho da população de larvas de Aedes sierrensis. Em contraste com outros grupos de patógenos de insetos que usualmente são ingeridos, fungos patogênicos penetram no tegumento do inseto e a cutícula é a maior barreira limitando doenças. As larvas morreram por infeç̧ðes secundárias, isso possivelmente esta correlacionado com a densidade de zoosporos na água. A competição intra específica das infeç̧ões secundárias afetam o número ou o tamanho dos mosquitos emergidos dessas interações pode ser a ligação do vetor potencial e seu hospedeiro, porém ressaltam que esta hipótese deve ser examinada em experimentos de laboratório.

KERWIN e WASHINO, 1988 avaliaram em campo Lagenidium giganteum, parasita facultativo de larvas de Aedes melanimon. As larvas hospedeiras foram mortas rapidamente em comparação com outros fungos entomopatogenicos, porque não é nocivo ao mosquito a menos que haja a emergência do adulto completo, o fungo usualmente tem mais tempo de desenvolvimento do que é necessário para obter controle 
adequado do hospedeiro. Em contraste com, gentes biológicos que controlam insetos e plantas frequentemente tem ação em um período curto para minimizar o perigo a planta. Este fungo permanece como um dos mais promissores agentes para operaçð̃es de controle de mosquito.

KRAMER, 1990 realizou 6 bioensaios para avaliar a eficácia do fungo Lagenidium giganteum contra larvas de mosquitos. Os fungos infectaram larvas de 4 gêneros e produziram mortalidade maior que $90 \%$. Fatores ligados a qualidade da água podem alterar a eficácia do fungo. Os bioensaios demonstraram que essa espécie de fungo tem potencial para o controle de espécies de mosquito com água relativamente limpa, podendo ser efetivos agentes de mortalidade em determinadas condiçð̃es.

PATEL e col., 1990 testaram 6 diferentes tipos e concentrações de formulaçð̃es e seu nível de infestação sobre larvas de Culex quinquefasciatus, observando que a concentração, viscosidade e a forma de uso dos fungos alteram a infectividade das larvas. Os fungos em formulaçð̃es encapsulados produziram similar infecção, mesmo em relação ao tempo de estocagem das cápsulas. A infectividade variou entre as formulaçð̃es chegando até a $100 \%$.

RUEDA e col.,1990 avaliou o fungo Lagenidium giganteum contra Aedes aegypti e Culex quinquefasciatus em recipientes artificiais como pneus, madeira e containers de concreto, em todos os estágios larvários, demonstrando diferenças entre os estágios, entre as C.quinquefasciatus e Ae.aegypti e entre os tipos de criadouros respectivamente: pneus ( $55-45 \%)$, madeira (67-38\%) e em container de concreto foi menor (17-14\%), esse resultado pode estar relacionado com a qualidade da água, além 
da idade das larvas, indicando a viabilidade do uso de fungos em programas de controle, ressaltando a necessidade de estudos sobre outras espécies de fungos.

CUEBAS-INCLE, 1992 demonstrou a infeç̧ão de mosquitos adultos Aedes aegypti pelo fungo entomopatogênico Erynia conica. Os cadáveres dos mosquitos produziram conidia que foi infectiva para outros adultos, apesar da infecção não ser maior que $12 \%$, os mosquitos morreram com sinais de micoses, demonstrando a suscetibilidade do mosquito ao fungo, indicando que há potencial uso dessa espécie de fungo no controle de mosquitos, requerendo maiores estudos e esforços para implementação. 


\section{BACILLUS sp.}

Com relação ao uso de bactérias do gênero Bacillus, conhecidas como produtoras de toxinas entomocidas, houve notável avanço a partir de 1977 com a descoberta e tipificação do Bacillus thurigiensis var. israelensis, de alta atividade larvicida para simulídeos e culicídeos de vários gêneros; constatou-se a ação larvicida na maioria das espécies de interesse médico- veterinário, incluindo os gêneros Anopheles, Culex, Aedes, Psorophora e outras espécies silvestres. Também foi o caso do Bacillus sphaericus, a partir de 1979, para controle de culicídeos dos gêneros Culex e Anopheles, com grande atenção para a reciclagem no meio ambiente (NETO e OLIVEIRA,1985).

Em geral, a alimentação das larvas de culicídeos consiste em microorganismos como bactérias, fungos, protozoários e detritos orgânicos animais ou vegetais. As verificações feitas em anofelinos e outros mosquitos levaram à conclusão de que o conteúdo intestinal representa amostra dos vários tipos de substancias, partículas e microorganismos encontrados na água em que vivem as larvas. Este fato tem aplicação prática no uso de compostos larvicidas. Estes sob a forma de po, quando espalhados na superficie da água e em vista da falta de seletividades, são ingeridos e exercem assim sua ação letal ( FORATTINI, 1962).

Em relação à persistência ambiental nada se constatou até o presente, não ocorrendo multiplicação e acumulação na cadeia alimentar. Os cristais até provável degradação no meio, são protoxinas inertes, ativando-se apenas nos hospedeiros 
específicos. O surgimento de resitência por seleção de B.t.i é improvável, segundo vários autores que realizaram experiências laboratoriais (NETO e OLIVEIRA, 1985).

Um fato revelado por HABIB, 1989 é a diferença de susceptibilidade, não apenas entre estádios larvários, mas também entre diferentes fases do mesmo estádio. Tal observação levou a recomendar o inicio do $4^{0}$ estádio larval para os bioensaios de padronização.

A ação seletiva do produto biológico preservando os agentes naturais de controle aliada ao menor risco do manuseio, são importantes vantagens adicionais sobre o uso de produtos químicos.

Atualmente já se pode constatar em várias situações que a utilização deste controle biológico assemelha-se em termos de resultados imediatos aos inseticidas químicos mais eficazes, superando-os no entanto pela pouca possibilidade de selecionar resistentes e preservação de inimigos naturais, o que conduz a uma necessidade de utilização menos frequeente pela menor alteração do ecossistema (NETO e OLIVEIRA, 1985).

Atualmente, o mercado internacional conta com a comercialização de produtos em formulaç̃̃es de granulados, líquidos e pó molhável desses agentes, além de perspectivas de pastilhas efervescente. Tal facilidade, além da eficiência, da estabilidade e da segurança para a fauna não-alvo, aumenta consideravelmente o potencial uso desses patógeno e de seu uso em vários países do mundo. No Brasil, inclusive, alguns órgãos públicos de alguns Estados como São Paulo e Rio Grande do Sul já começaram usar tais produtos (HABIB, 1989) 
Há necessidade de mais observaçðes comparativas entre larvicidas químicos e biologicos para controle dos culicídeos nas diversas condiçð̃es dos criadouros. Ainda que as formulaçðes biológicas tenham inegável vantagens devido à segurança de uso e especificidade no meio, é necessário que se elucide a questão da eficiência dos programas. Para tal, temos que investigar excessivamente o possível efeito prolongado das aplicaçðes, bem como a produção local a custos menores do que a atual importação (NETO E SILVEIRA, 1989).

A maior desvantagem econômica dos bacilos é a baixa estabilidade após a aplicação nos criadouros. O desempenho em campo é altamente influenciado pela presença de matéria orgânica sólida na água (MARGALIT e DEAN, 1985).

O futuro desses agentes está ligado ao melhoramento genético. Os esforços combinados de geneticistas, microbiologistas e entomologistas, promoveram o surgimento de uma nova estratégia de controle.

VAN ESSEN e HEMBREE, 1980 determinaram o efeito da idade das larvas de Aedes aegypti e Aedes taeniorhynchus e sua suscetibilidade ao B.t.i, em condições de laboratório. Aedes aegypti foi mais suscetível à bactéria que Ae.taeniorhynchus em todas as fases larvais. As larvas mais jovens de ambas espécies foram mais suscetíveis que as mais velhas. A comparação da suscetibilidade de varias espécies de mosquitos é dificultada pela diversidade de métodos de estudos, que reportam apenas a mortalidade. Um longo período de estudos seguido de perto é necessários para elucidar alguns fenômenos, como a redução da longevidade do adulto e a fecundidade dos indivíduos que sobreviverem ao tratamento. 
MERRISN e AXTELL, 1983 investigaram uma formulação comercial de B.t.i no controle de larvas de Aedes taenorhynchus. A aplicação da formulação produziu 100\% de controle 1-2 dias após o tratamento. Sendo efetivo nas concentraçð̃es testadas, sendo necessário que se conheça uma concentração adequada para os criadouros a serem tratados.

MULLA e col., 19844 novas formulaçð̃es de B.s. renderam excelente controle de mosquitos Psorophora columbiae e Aedes nigromaculis. As larvas de P.columbiae foram altamente suscetiveis ao larvicida microbiano, sendo por isso considerado como agente promissor de biocontrole.

McLAUGHLIN e VIDRINE, 1984 a dispersão de 3 formulaçðes de B.t.H-14 forma comparadas em testes de campo contra larvas de Psorophora columbiae, em águas de irrigação. Não houve diferença significativa na dispersão ocorrida ou na porcentagem total da área alagada. Este estudo resultou num novo método de testes para agentes de controle biológico, dependendo efetivamente da área tratada, não foi detectada diferença na dispersão das 3 formulações.

MULLA e col., 1984 duas preparaçð̃es de B.s. 2362 foram avaliadas quanto à eficácia e permanência contra larvas de mosquitos. Todas as preparaçðes avaliadas demonstraram excelente atividade contra larvas de $4^{\circ}$ estagio de Culex quinquefasciatus em laboratório. $\mathrm{O}$ efeito inicial bem como a longevidade dos extratos pode promover $\mathrm{o}$ aumento direto de técnicas de formulaçðes. Este trabalho evidencia que alguns extratos a base de $B . s$. demonstram uma boa atividade larvicida, oferecendo um bom potencial de uso em programas de controle. 
LACEY e col.,1984 formulações aquosas de B.t. H-14 e B.s. 2362 foram comparadas quanto à atividade contra criadouros peridomiciliares de Culex quinquefasciatus. Todos os tratamentos de B.s. dão aproximadamente uma redução inicial completa das larvas. $\mathrm{O}$ uso de formulaçães no formato de pílulas pode ser vantajosas em programas de trabalhos intensos em desenvolvimento para um longo e permanente controle em criadouros.

MULLA e col., 1984 avaliaram em condiçães de laboratório extratos de B.s. contra larvas de $2^{\circ}$ e $4^{\circ}$ estagio de 5 espécies de mosquitos. Todos os extratos exibiram alto nivel de atividade contra larvas do gênero Culex. Demonstrando que as larvas de $2^{\circ}$ estagio são geralmente mais suscetiveis que as do $4^{\circ}$ estagio, sendo a mortalidade máxima atingida 48 horas após o tratamento. Houve $90 \%$ de mortalidade em Cx.quinquefasciatus. Em condiçðes de campo permitiu excelente controle inicial de $C x$. tarsalis e Cx.peus, este controle persistiu por 14 dias. Indicando que podem promover um controle satisfatório, sendo afetado pela densidade larval e outros fatores como qualidade da água, $\mathrm{pH}$ e a temperatura da água, que em programas de controle devem ser bem conhecidos.

MCLAUGHLIN e VIDRINE, 1985 identificaram os fatores hidrológicos que influenciam na distribuição do larvicida, e estabeleceram produtos para o tratamento baseados nesses fatores, permitindo flexibilidade para ajuste individual de cada tipo de criadouro. O principal fator hidrológico e topográfico determinante na dispersão da concentração de formulaçð̃es de $B . t \mathrm{H}-14$ foi o numero de áreas inundadas, a quantidade de níveis de água corrente no inicio do tratamento e o numero de recipientes e área inundada em 24 horas. Essas informaçðes são necessárias para o uso desse método. Esse 
procedimento permitiu uma maior flexibilidade no tratamento em determinadas condiçðes. Sendo que requer uma melhor analise.

SANDOSKI e col., 1985 avaliaram um produto comercial de B.t.i. spray por aplicação aérea contra populações naturais de Anopheles quadrimaculatus, durante o verão. A redução da população esteve entre 21,8 - $97,9 \%$ de acordo com a concentração de cada tratamento. Este estudo confirma o potencial dessas formulaçðes como efetivo e econômico meio de tratamento de grandes áreas com B.t.i., além de ser um larvicida ambientalmente compatível. Estudos adicionais são necessários para determinar o efeito do aumento da extensão do campo, teoricamente reduzirá o necessário para o controle da população de mosquitos adultos, já que as larvas podem ser controladas em larga escala.

LYSENKO, e col., 1985 descreveram a atividade larvicida de 5 novos extratos de Bacillus sphaericus contra larvas de mosquitos, lepidópteras e gafanhotos. Os 5 extratos descritos neste trabalho foram primeiro altamente letais para larvas de mosquitos e outros insetos aquáticos. Recomendam que B.s. isolados encontrados associados com insetos sejam submetidos a determinação da atividade larvicida, para melhor avaliação.

NOVAK e col., 1985 testaram a duração do efeito de controle de larvas de Aedes aegypti usando formulações de Temephos e B.t.i. Neste estudo foi efetivo no controle, mas a duração do controle não aproximou do observado com formulações de Temephos. Como a eficácia temephos, as formulaçð̃es granulares de B.t.i em pneus foram afetada pela soma de toxinas usadas. A mortalidade atingiu $100 \%$ em 48 horas de exposição. Estes resultados indicam que ambas toxinas podem ser efetivas por longos períodos de controle. Assim seu uso em programas de controle integrado é uma boa alternativa. 
JONES e LLOYD, 1985 determinaram a eficácia de formulações de B.t. (H-14) em estágios tardios de Aedes dorsalis, Ae.fitchii e Ae.melanion. baixas temperaturas causaram a diminuição na eficácia das formulações testadas em laboratório, e em temperaturas extremas de primavera diminuíram a eficácia nos testes de campo. $O$ controle adequado de larvas de $4^{\circ}$ estagio foi obtido em estudos de campo no período de 24 horas quando a temperatura era maior ou igual $12^{\circ} \mathrm{C}$ em um tratamento de $0,1 \mathrm{mg} / \mathrm{L}$. nas porçðes da época de desenvolvimento larval, quando as temperaturas noturnas caem ate um determinado ponto, as formulações de B.t.i. serão efetivas adicionas ao arsenal de controle.

LACEY e INMAN, 1985 avaliaram a atividade larvicida de 3 produtos comerciais de formulações granulares de B.t. (H-14) contra Anopheles crucians e An.quadrimaculatus. $\mathrm{O}$ aumento das concentrações das formulaçðes testado levou ate $100 \%$ de mortalidade. A eficácia dessas formulaçð̃es suprime as populaçð̃es de mosquitos vetores, que são altamente resistentes ao controle químico convencional.

LACEY e col., 1986 avaliaram experimentalmente formulaçð̃es de Bacillus sphaericus contra mosquitos utilizando um spray comercial. A redução da população larval de Anopheles quadrimaculatus 48 h $(71$ - 82\%) e 1 semana após aplicação foi significante chegando a $98 \%$.

APPERSON e col., 1986 avaliaram a eficácia de B.t.i. em poças de matas contra larvas de Culex sp., sendo a formulação ativa contra varias espécies desse gênero. $O$ resultado desse trabalho indica que essas formulaçðes promovem um sustentável controle desse gênero, sendo formulaçðes altamente apropriados para o uso em vários criadouros artificiais ou naturais. 
HARE e NASCI, 1986 investigaram os efeitos de concentrações subletais de B.t.i. em larvas de $2^{\circ}$ estagio de Aedes aegypti. A morte das larvas demonstrou que a disponibilidade de comida afeta significantemente o desenvolvimento larval e a sobrevivência. $\mathrm{O}$ tratamento com dose sub-letais de B.t.i. desenvolveu sobreviventes tão rapidamente como as larvas não tratadas e produziu um numero significante de adultos.

PERICH e col., 1987 determinaram em bioensaios a eficácia de MSF ( molecular surface film) combinado com preparaç̃es comerciais de B.t.i contra larvas, pupas e ovos de Anopheles albimanus. O MSF foi eficiente sozinho contra ovos, larvas de $4^{\circ}$ estagio e pupas, 48 horas após o tratamento, mas tem efeito limitado em larvas mais jovens. A eclosão de ovos foi reduzida aproximadamente $25 \%$ com todas as formulaçðes contendo MSF. Todas as formulaçð̃es combinadas produziram mortalidade maior que $90 \%$ em todos os estágios larvais e pupas 48 horas após o tratamento. Oferecendo uma alternativa potencial no controle.

ALY e col., 1987 descreveram o desenvolvimento e atração superficial de formulaçðes de B.t.i para o controle de larvas de Anopheles sp. A combinação de dois atrativos: um sinal da toxina primaria na zona de alimentação das larvas e a adição de uma partícula mensageira gustatória, resultaram em substancial aumento da eficiência de B.t.i contra larvas de anopheles sp. De qualquer modo, o número de problemas técnicos e a dificuldades associados com a proporção de aplicação, devem ser investigados e resolvidos, para uma melhor recomendação.

BERRY e col., 1987 avaliaram 9 formulações comerciais de Bacillus thurigiensis var. israelensis e 2 de Bacillus sphaericus como larvicidas contra larvas de mosquitos 
comuns. Todas as formulaçð̃es de B.t.i. foram efetivas chegando a uma redução de até $100 \%$ (90-100\%) em Aedes vexans e Culex sp. em seu habitat natural, as formulações com B.s. chegaram a $90 \%$ de redução (84-98\%) em populações de Aedes sp. e. Culex sp.

KRAMER e col., 1988 avaliaram o potencial de controle do peixe Gambusia affinis e da bactéria Bacillus thurigiensis var.israelensis, que realizaram significante redução na densidade da população. A formulação granular do B.t.i. reduziu efetivamente a população de mosquitos, na presença do peixe, a população larval não reagiu após o tratamento com B.t.i. Portanto o efetivo controle poder se conseguido quando estoque de campo de peixes for de $1.1 \mathrm{Kg} / \mathrm{ha}$, monitorando e tratando com B.t.i., quando a população de larvas estiver acima do nível aceitável.

MULLA e col., 1988 testaram seis formulações de $B . s$ no controle de larvas de Culex sp. em lagoas. Todas as formulaçðes foram eficazes. Algumas formulaçð̃es mais ativas que outras, rendendo excelentes controle inicial e persistência maior que $80 \%$ por $14-21$ dias com um tratamento. Este estudo explica que este agente tem grande promessa de controle de mosquitos em água poluída. De qualquer modo, para um bom controle inicial e persistência da ação, a taxa de aplicação tem ser aumentada de $5-10$ de acordo com a qualidade da água. Este aumento na aplicação é justificado por um controle durável obtido com apenas um tratamento, reduzindo os custos econômicos de inspeção e repetição de tratamentos com menor persistência de agentes que promovem controle por apenas $3-7$ dias.

BASSI e col., 1989 determinaram a mortalidade inicial causada pela aplicação de duas formulações comerciais de B.t.i. sobre Psorophora columbiae e Anopheles 
quadrimaculatus, atingido uma mortalidade de $75 \%$, havendo diferenças entre as formulaçð̃es e espécies de mosquitos.

WALLACE e col., 1989 estudaram a eficácia de formulação granular de Bacillus thurigiensis (H-14) contra larvas de mosquitos. O primeiro tratamento com 370 larvas de $3^{\circ}$ estagio de Aedes taeniorhynchus coladas em latas. Os resultados obtidos com amostras retiradas dessas latas foram irrelevantes, pois se recupera uma ou outra larva, ou ocasionalmente um grande numero quando as larvas estão agregadas. A densidade de larvas e pupas dificultou a avaliação da emergência dos adultos, que foi usada como media para avaliar a atividade larvicida. A porcentagem de emergia dos adultos esteve entre $18,4-86,9 \%$ de $1-6$ dias e $20-72 \% 7-11$ dias.

JONES e col., 1990 determinaram a dose efetiva e persistência do B.sohaericus contra Culex quinquefasciatus em água contaminada. A maior redução larval foi observada após $\mathbf{4 8}$ horas com redução maior que $\mathbf{8 0 \%}$. Possivelmente a redução da luz solar e corrente de água, quantidade de chuva, resíduos sólidos em suspensão, poluição, vegetação, $\mathrm{pH}$, e oxigênio dissolvido tem algum efeito na atividade larvicida e persistência do agente microbiano.

ARREDONDO-JIMÉNEZ e col., 1990 em criadouros experimentais simularam condiçðes naturais para avaliar a eficácia de 2 formulaçð̃es de B.s. contra Anopheles sp. e Culex sp. Em laboratório testes com formulações granuladas e líquidas demonstraram que $4 \mathrm{mg} / \mathrm{l}$ é a dose mínima letal para algumas espécies 48 horas após o tratamento. Anopheles albimanus foi 20 - 30 vezes mais tolerante ao B.s. que Culex quinquefasciatus. O aumento da concentração para formulações usadas por 3-4 meses contra Culex sp. e An.albimanus demonstrou que em planejada estratégia de controle efetivo, 4 aplicações 
por ano com doses de $2,0 \mathrm{~g} / \mathrm{m}^{2}$ seriam suficientes para manter os níveis de redução de aproximadamente $70 \%$.

MATANMI e col., 1990 avaliaram o destino e persistência de duas formulações comerciais de B.s., em lagoas de fazendas contra Culex stigmatosoma, obtendo redução de $90 \%$ por 4 semanas. Seus resultados indicam um extensivo controle obtido após a ingestão de esporos da superficie da água e lama pelas larvas. Além da possibilidade de reciclagem que é um importante fator no controle de mosquitos.

BOWLES e col, 1990 avaliaram formulações de Bacillus sphaericus contra larvas de Psorophora columbiae. Todas as formulaçð̃es testadas forneceram um bom controle maior que $84 \%$ em todos os estágios 2 dias após o tratamento; em 10 dias o controle foi maior que $70 \%$., indicando que B.s. pode ser um efetivo agente de controle desses mosquito. De qualquer modo, os efeitos de baixas dosagens, colocação do esporo, e qualidade da água na eficiência de formulações de B.s. permanecem para serem testadas.

LORD e FUKUDA, 1990 testaram formulações de Bacillus sphaericus 2362 e B.thurigiensis var. israelensis contra Mansonia titillans e Ma. dyari. A suscetibilidade das duas espécies de bactérias individualmente foi similar, com variações nas DL50. a exposição das larvas de Mansonia. As concentrações adequadas dessas formulaçðes geram uma dificuldade no controle. Esse controle requer um sistema que penetre na folhagem do criadouro.

PERICH e col., 1990 avaliaram a eficácia e compatibilidade do controle integrado de B.t.i. e a planaria Dugesia dorotocephala contra larvas de Aedes taeniorhynchus em condições de laboratório. Os dois tipos de controle demonstraram 
serem eficientes isolados ou integrados, quando integrado o B.t.i. tem $100 \%$ de eficácia e a planaria mantém a população em baixos níveis. Podendo concluir que o B.t.i.não tem efeito prejudicial sobre a planaria predadora, podendo ser utilizado no controle integrado de mosquitos. O tratamento combinado mostra-se como potencial alternativa de estratégia de controle, permitindo novos estudos em condiçð̃es de campo.

PERICH e col., 1990 foram avaliadas contra larvas capturadas em ambiente natural de Anopheles albimanus 4 formulaçð̃es biológicas combinadas com produtos de eficácia conhecida. Todas as formulações reduziram as populações larvárias 48 horas após o tratamento, continuando por 10 dias. Os resultados desse estudo indicam que essas formulações oferecem um excelente controle como uma alternativa biológica, nas estratégias de controle.

MEISCH, 1990 conduziram por 4 anos um estudo para determinar a eficácia de formulações de B.t.i. contra larvas de Psorophora columbiae. Promovendo um excelente controle com altas dosagens, geralmente entre $85 \%$. De qualquer modo essas formulaçőes requerem testes adicionais para determinar limites mínimos mais econômicos para o controle. Decisões de tratamentos baseadas em informações especificas resultarão em redução dos custos, materiais e aplicação.

LORD, 1991 testou uma formulação de Bacillus sphaericus de pílulas com óleo vegetal parcialmente hidrogenado. Esta formulação aumentou a ação residual contra Culex spp. em larga e pequena escala, mesmo em água poluída. Em 5 dias as larvas foram eliminadas. Estas pílulas de B.s. oferecem uma liberação gradual de toxinas. A inclusão de uma pequena porção de polímeros superabsorventes permitiu a quebra das pílulas sem a imediata dispersão da bactéria que ocorre com formulaçð̃es em pó e 
líquidas. Um importante fator de limitação da atividade residual é a colocação da bactéria no substrato.

LAGO GM. et al, 1991 comprovaram a efetividade do Bacillus sphaericus em formulaçðes líquidas em diferentes criadouros, obtendo resultados de uma alta efetividade entre $24-72 \mathrm{~h}$ de aplicação ocasionando $100 \%$ de mortalidade sobre larvas de Culex quinquefasciatus e Anopheles albimanus em laboratório, sendo as larvas de $1^{2} \mathrm{e}$ $2^{\circ}$ estágio as mais suscetiveis. Durante os ensaios de campo observaram a inocuidade do larvicida sobre a fauna associada.

ANDRADE e MODOLO, 1991 testaram a suscetibilidade de larvas de $4^{\circ}$.e $3^{\circ}$. estagio de Aedes aegypti contra as formulaçðes de B.t.i. e ao Temephos. As Larvas $3^{\circ}$ foram mais suscetiveis que as no inicio ou fim do $4^{\circ}$ estagio. Já o Temephos demonstrou uma possivel resistência. A mistura de B.t.i e Temephos demonstrou que a DL50 é equivalente ao B.t.i. sozinho. Assim o controle intergado apresenta algumas vantagens, como a economia no tratamento e a redução de uma possivel resistência, sendo o monitoramento constante necessário.

WILMONT e col., 1993 avaliaram formulaçð̃es comerciais de B.t.i. para o controle de Aedes sp.. em poças de matas. Não houve diferença significante entre as duas formulaç̃es, ambas forneceram grande controle de 90 e $98 \%$. Em programas de larga escala, a aplicação poderá reduzir a densidade populacional porem outros fatores poderão afetar a eficiência do tratamento. Neste trabalho podemos observar que aplicação foi eficiente proporcionando um bom controle.

ALI e col., 1994 avaliaram a eficácia e atividade residual de 6 formulaçðes a base de B.t.i. contra larvas de $3^{\circ}$ e $4^{\circ}$ estagio de Aedes taeniorhynchus em bioensaios 
usando reservatórios encontrados em lavanderias. Essas formulações forneceram aparentes mortalidades acima de $75 \%$ em 9 dias após o tratamento com indicações de terem maior atividade prolongada. O método utilizado nesse trabalho demonstra a eficiência e persistência dessas formulações.

NASCI e col., 1994 investigaram a habilidade de formulaçóes larvicida e regulares de crescimento de Aedes albopictus foi investigada em campo, obtendo níveis de controle de ate $100 \%$ por 150 dias. Esses resultados sugerem que longos períodos de controle podem ser alcançados com uma aplicação. Apesar de econômico, este método de controle não é apto para ser usado em programas de grandes cidades. Pode ser usado, preferencialmente, para obter sucesso se usado moderadamente, em grandes infestações residenciais.

SANTOS e col., 1994 utilizaram para o controle biológico de mosquitos em um cemitério em Campinas um produto comercial a base de Bacillus thurigiensis var. israelensis. Foram feitas três aplicações, obtendo uma eficácia de $98,47 \%$, em media aproximadamente $99,8 \%$ de controle. O produto apresentou baixo efeito residual dos formulados em suspensão aquosa, e ainda as dificuldades operacionais dos tratamentos em ambientes como cemitérios, a eficiência em apenas uma aplicação pode ser baixa, da ordem de $65 \%$ tendo uma ação seletiva, com fácil manuseio e aplicação. Em programas de manejo pode-se também somar a esse método, a utilização de areia e conscientização da população freqüentadora dos cemitérios.

RUAS-NETO e col., 1994 utilizando larvas de Culex quinquefasciatus foram tratados em laboratório e no campo com formulações de Bacillus thurigiensis var. israelensis e B.sphaericus e formulações químicas de piretróides e organo-fosforados. 
As formulaçðes biológicas apresentaram bons resultados em laboratório e foram consideradas adequadas assim como em condições naturais pois supera influencias fisicas, problemas de resistência e eliminação e inimigos naturais e ausência de efeito residual.

REGIS e col., 1995 avaliaram o efeito da ação de controle em população de Culex quinquefasciatus, enfatizando o controle biológico com Bacillus sphaericus que demonstrou boa eficácia promovendo um excelente controle inicial quando usado em águas poluídas. Persistindo por um mês nos mais diversos criadouros. De qualquer modo as características estruturais dos criadouros, a inspeção não foi favorável quanto a persistência do controle por longos períodos, direcionando para a necessidade de aplicaçð̃es freqüentes.

REGIS L. et al, 1996 executaram um projeto controle integrado de filariose no Recife, que incluía tratamento em massa dos habitantes com uso de remédios; medidas físicas e mecânicas de vedação de fossas e o controle biológico do vetor com Bacillus sphaericus que melhor se adapta a altas cargas de poluição orgânica no criadouro. Todas essas medidas resultaram em diminuição da população de mosquitos, que foi verificada após dois anos. $\mathrm{O}$ inseticida bacteriano é uma importante arma no controle de mosquitos associada à outras medidas.

GROUVES RL e MEISCH MV, 1996 avaliaram Bacillus sphaericus contra 7 espécies de mosquitos Aedes aegypti, Ae.albopictus, Ae.vexans Anopheles punctipennis, Culex quinquefasciatus, Cx.restuans e Psorophora columbiae. Em laboratório demonstram atividade contra todas as 7 espécies com diferenças entre os estágios de desenvolvimento; a mortalidade foi observada 24 e $48 \mathrm{~h}$ após o tratamento. Em campo a 
mortalidade não excedeu $16,7 \%$ após $48 \mathrm{~h}$ de tratamento, em $24 \mathrm{~h}$ não diferiu estatisticamente do grupo controle. Estes experimentos demonstraram o potencial desses agente como larvicida. A menor concentração requerida para evocar uma mortalidade de $90 \%$ contra Ps.columbiae é aproximadamente $0,1 \mathrm{ITU} / \mathrm{ml}$. A rápida resposta obtida nessas dosagens mínimas favorecem o aumento da eficácia do B.s. como um agente adequado para o biocontrole.

CONSOLI e col., 1997 avaliaram a eficácia de uma nova formulação de Bacillus sphaericus produzida em conjunto pela Fundação Oswaldo Cruz e INPAL ind. Química, contra Culex quinquefasciatus. Em todos os ensaios houve controle populacional entre 70,6 e $97,9 \%$. Sendo compatível com outras formulaçðes já testadas com o mesmo agente de controle.

RODRIGUES e col., 1998 realizaram bioensaios em condições de laboratório para testar 10 extratos de Bacillus sphaericus, isolado no Brasil, contra larvas de $3^{\circ}$. estagio de Anopheles nuneztovari e An.darlingi, demonstrando relativa atividade em 24 e 48 horas exposto a bactéria. Houve diferenças entre os extratos sendo alguns mais efetivos que outros. Esses extratos brasileiros demonstraram grande atividade larvicida, na região amazônica, em relação as espécies vetoras de malaria.

CASTRO e col., 2000 implementaram e avaliaram o emprego do controle biológico com B.sphaericus contra os vetores da malaria. Se determinou a capacidade do mencionado biopraguicida para reduzir as densidades larvárias desses insetos. Obtiveram uma redução de 94,57\% total sobre Anopheles albimanus, após 4 meses de aplicação. Os resultados obtidos neste trabalho coincidem com os reportados por estudos 
similares, desta forma permitiu recomendar a aplicação do biolarvicida, como parte de um programa de controle integrado para espécies de mosquitos. 


\section{ESTERELIZAÇÃO E ALTERACOES GENETICAS}

BAILEY, 1979 foi desenvolvida tecnologia para esterilizar e embalar 1 milhão de machos de Anopheles albimanus por dia para liberação no campo. A media machos estéreis produzida durante um período de 1-5 anos foi de $98,8 \%$. A mortalidade no transporte especialmente desenvolvido em media nas gaiolas $4,5 \%$ por 72 horas de idade dos adultos e 2,5\% para 24 horas. Esta técnica de controle requer técnicas mais elaboradas para que se recomende o uso em programas de controle.

FINE e col., 1979 determinaram um modelo que prediz o efeito de várias estratégias de controles genéticos em populaçð̃es isoladas de mosquitos que sofrem extremas flutuaçð̃es sazonais. A descrição inclui métodos que simulem as variaçð̃es sazonais e o tempo de desenvolvimento e reprodução baseadas em populaçðes normais, e associado à suposição de densidade dependente com variado reprodução independente da densidade.

SHAHID e CURTIS, 1987 introduziram no genoma original de Culex quinquefasciatus no citoplasma de Cx.pipens. os machos resultantes demonstraram incompatibilidade com as fêmeas. Gerando uma forma de controle que deve ser melhor avaliada. 


\subsection{USO DE PLANTAS}

A influencia de plantas aquáticas em criadouros de mosquitos te sido observada e estudada. Alguns gêneros de mosquitos são limitados em águas contendo vegetação e folhagem (HOBBS e MOLINA, 1983). Em testes de campo para quantificar presença da pteridofita aquática Salvinia auriculata observando o prejuízo à população de Anopheles albimanus em seu criadouro natural. Testes de laboratório indicaram que esta planta pode ser uma barreira para as fềmeas grávidas, interferindo diretamente na oviposição, conseqüente na sua proliferação. Sugerem que a planta possa ser considerada como um forte meio natural controle em certos tipos de criadouros.

MARTEN, 1987 observou que muitas espécies de algas são bons alimentos para larvas de mosquitos, mas algumas espécies são virtualmente indigestas para as larvas. Essa características não tem sido reconhecida porque em abundância as algas usualmente se combinam com outras espécies que promovem uma nutrição suficiente. Năo pode afirmar que fitoplancton provara na pratica que em larga escala controlara mosquitos, mas ele poderá ser melhor explorado.

As plantas ainda podem conter princípios que atuam como inseticidas. 


\section{DISCUSSAO}

É na fase adulta que os mosquitos desempenham seu papel de importância na Saúde Publica. Nesta fase as fêmeas realizam o repasto sanguíneo, necessário para a maturação dos ovos. E também nesta fase que em altas densidades tornam-se agentes de incômodos pela sua hematofagia. As estratégias de controle desta fase estão restritas ao controle químico e as medidas de controle mecânico, evitando-se o contato com repelentes e mosquiteiros.

Apesar de todos os problemas estarem relacionados ao adulto, é na fase imatura que eståo baseadas a maioria das estratégias de controle, em virtude de seus criadouros limitados.

Podemos dizer que os culicídeos são "democráticos" pois atingem todas as camadas sócio-economicas e culturais, independente de sexo, raça, escolaridade, etc. Possuem ampla distribuição espacial incluindo peridomiciliar e intradomiciliar, podendo inclusive adquirir hábitos domiciliares (endofilia). São afetados pelos ciclos nictemeral e sazonal. As espécies alvo deste estudo são antropofilicas, endofagicas e exofágicas.

De maneira geral desde a pré-histórica o homem tem tentado se livrar do incomodo causado pelos mosquitos como seu barulho e picadas. Com o progresso os mosquitos também se tornaram vetores de algumas doenças, assim manter distancia desses insetos passou a ser cada vez mais necessário.

Com o surgimento dos inseticidas químicos, aliado a sua comodidade e praticidade, já que o uso nos livrava do incomodo, as medidas de controle biológico foram deixadas de lado, sendo gradativamente abandonadas. 
Porém o crescimento desenfreado da resistência dos mosquitos aos inseticidas e a preocupação com questões ambientais, gerou uma pergunta. Como controlar as populações de mosquitos, diminuindo principalmente a transmissão de algumas doenças. A resposta já era conhecida na natureza, o emprego de inimigos naturais. Assim novas pesquisas foram feitas para avaliar e quantificar a utilização de cada agente potencial para o controle biológico. Isso observando a capacidade de controle de cada agente individualmente ou de forma integrada com outros agentes biológicos, com agentes químicos ou mesmo associados ao manejo mecânico.

No controle biológico a introdução de organismos que afetem a proliferação excessiva de mosquitos, não é uma idéia inovadora. Não podemos esquecer que a natureza sem a interferência humana se encarregava de manter as populaçð̋es em equilíbrio em seu ecossistema, porem com a evolução humana isso foi se tornando impossível.

Durante este trabalho podemos perceber que as principais categorias de controle são os predadores, os parasitas e principalmente os que tem recebido maior atenção dos pesquisadores das industrias as bactérias do gênero Bacillus.

Ainda que as formulações biológicas tenham inegáveis vantagens devido à segurança de uso e especificidade no meio, é necessário que se elucide a questão da eficiência dos programas em situaçðes reais, assim como seu custo de produção em massa e aplicação. No campo em todos os tipos de criadouros, já que falamos em incômodo, a população humana, principalmente nos grandes centros urbanos onde há uma grande quantidade de criadouros potenciais, sem mencionar uma maior concentração de pessoas o que dificulta a implementação de métodos alternativos, haja 
visto que a colaboração da população, com a manejo mecânico é fundamental para o sucesso de qualquer que seja a estratégia de controle.

As estratégias de controle de mosquitos vetores,devem ser globais, pois os mosquitos não reconhecem fronteiras, assim o controle dependerá conseqüentemente do entendimento da dinâmica das populações de mosquitos. Levando se em consideração as oscilações climáticas de cada região e a sazonalidade do mosquito.

O conhecimento da biologia do mosquito assim como sua adaptação ou evolução às condições humanas e sua proximidade em relação aos nossos hábitos não podem ser deixadas de lado já que as medidas de controle devem ser tomadas em relação a todos esses fatores. Assim como também o conhecimento da biologia e as principais características do bioagente a ser empregado, levando em consideração principalmente às características do criadouro como: matéria orgânica disponível, poluição, principais produtos dessa poluição, oxigênio dissolvido, quantidade de água e tempo de permanência dessa água, presença ou ausência de amônia, temperatura da água, coloração da água, dentre outros.

O cenário ideal para a proliferação de mosquitos esta relacionado: a pobreza, a continua imigração humana resultante da desordenada urbanização e a fatores ambientais como chuvas, altas temperaturas e umidade ao longo do ano, o que dificulta a manutenção da população de mosquitos em níveis considerados adequados.

Devemos salientar a necessidade de mais observações comparativas entre larvicidas químicos e biológicos para o controle de culicídeos nas mais diversas condições de criadouros. 
Quanto aos agentes de biocontrole bacterianos, estamos falando em varias formulaçð̃es e modos de aplicações pré-estabelecidos, será que neste caso podemos classifica-los como controle químico ou biológico? Levando -se em consideração seus resultados satisfatórios e persistência. Será que haverá uma pressão de seleção de mosquitos levando a resistência?

Como foi observado na grande maioria de trabalhos relacionados aos agentes de controle conhecidos como biolarvicidas, as bactérias do gênero Bacillus. tem chamado a atenção das industrias químicas e dos laboratórios de pesquisas, quanto ao desenvolvimento de formulações, com diferentes concentrações e apresentações de uso adaptando -se as mais variadas condiçðes. Desta forma foge uma pouco do que é concebido como controle biológico. Porém suas vantagens conhecidas como: especificidade não afetando os demais organismos, e sua atuação os coloca de volta a condição de bioagente. Esta é uma das questões a serem discutas e melhor avaliadas, já que se tratando de formulaçð̃es manipuladas e até mesmo artificiais podem gerar a resistência; uma vez que a resistência é resultante de uma pressão de seleção.

O controle biológico não é substituto do controle químico, mas o que se pode afirmar é que ambos podem conviver simultaneamente.

Antes que se recomende qualquer alternativa de controle biológico todas as variáveis que possam alterar sua eficiência individual ou integrada devem ser bem conhecidas, para que se possa obter sucesso e persistência desse controle.

No Brasil como temos um clima tropical; os agentes recomendados para o controle devem suportar grandes variações de temperatura; uma das alternativas seria o uso de agentes autóctones. 
Identificando a região e a climatologia da área a ser tratada, os principais tipos de criadouro, desta forma podendo realizar um trabalho bem direcionado.

Em criadouros permanentes poderíamos usar agentes como predadores e parasitas, peixes, nematodas, copépodos, crustáceos, dentre outros que realizam os seu ciclo de vida no próprio criadouro, realizando assim um espécie de reciclagem. Em criadouros artificiais semi permanente como ocos de arvores, latas e recipientes que possam acumular água, além do manejo mecânico, que é essencial, poderiamos utilizar agentes como as formulações de Bacillus, fungos que destroem as larvas, agindo como um 'regulador de crescimento; além dos extratos vegetais. Em caixas d'água e piscinas abandonadas que segundo a SUCEN (Superintendência de Controle de Endemias) são os criadouros mais importantes na Grande São Paulo. Devemos reavaliar essas praticas, já que essa água deve estar próprio para o consumo humano.

As estratégias que envolvem esterilização e manipulação genética esbarram em um problema que é custo. Esta tecnologia envolve grande investimento financeiro esta é uma desvantagem, já que para ser considerado um bom agente de biocontrole uma de suas características deve ser o baixo custo. 


\section{CONCLUSAO}

Identificamos com potencial de utilização no controle biológico de culicídeos.

1. predadores como: copépodos, peixes, larvas de Toxorhynchites $s p$, camarão, planarias;

2. parasitas como: nematodas, fungos;

3. as formulações de Bacillus sphaericus e Bacillus thurigiensis var.israelensis.

O uso de controle biológico nas Américas é mais estudado nos Estados Unidos em áreas de arroz e águas poluídas, em Cuba enfatizando bioagentes de predação como peixes e Bacillus sp. No Brasil temos trabalhos nas áreas de predação e formulações de Bacillus sp.

$>$ Em relação ao Brasil para que se recomende o uso de controle biológico devemos avaliara primeiro a área de aplicação e suas condições ambientais e então recomendar um agente adequado. Levando em consideração todas os aspectos bioecologicos dos agentes de controle biológico, e se adaptam as condições ambientais da área a ser tratada.

No Brasil podemos recomendar algumas estratégias como: em criadouros permanentes podemos recomendar agentes que completem seu ciclo de vida, podendo reproduzir, no criadouro, havendo assim uma reciclagem desse agente como: peixes, copépodos, crustáceos, planarias, nematodas e alguns fungos. Para criadouro semi permanentes e artificiais e recipientes como latas, pneus, garrafas, 
vasos e etc o típicos de tipo de controle mais eficiente seriam as formulações a base de Bacillus sp.

$>$ Cada tratamento e potencial larvicida de cada agente depende diretamente das condiçð̃es do criadouro e da espécie considerada alvo.

Para obtermos sucesso na aplicação do controle biológico, deve se levar em conta fatores ecológicos e socioeconômicos. Não basta ser um agente eficaz, esta eficácia deve ser comprovada em campo, assim como a viabilidade de sua produção em massa e aplicabilidade. 


\section{REFERENCIAS BIBLIOGRAFICAS}

ALI A, MULLA MS. Evaluation of the palanarian, Dugesia dorotocephala, as a predator of chironomid midges and mosquitoes in experiment ponds. Mosquito News $1983 ; 43$ (1): $46-49$.

ALI A, XUE R, LOBINSKE R, CARANDANG N. Evaluation of granular comcob formalations of Bacillus thuringiensis serovar israelensis against mosquito larvae using a semi-field biossay method. J. Am. Mosq. Control Assoc. 1994; 10 (4): 492-495.

ALY C, MULLA MS, SCHNETTER W, XU BZ. Floating bait formulations increase effectiveness of Bacillus Thuringiensis var. israelensis against anopheles larvae. J. Am. Mosq. Control Assoc. 1987; 3 (4): 583-588.

ANDRADE CFS, MODOLO M. Susceptibility of Aedes aegypti larvae to temephos and Bacillus Thuringiensis var. israelensis in integrated control. Rev. Sáude públ. 1991; 25 (3): 184-187.

ANDREADIS TG, GERE MA. Laboratory evaluation of Acanthocyclops vernalis and Diacyclops bicuspidatus thomasi (Copepoda: Cyclopidae) as predators of Aedes canadensis and Ae. Stimulans (Diptera: Culicidae). J. Med. Entomol. 1992; 29 (6): 974979.

ANDREADIS TG. Infection of a field population of Aedes cantator with a polymorphic microsporidium, Amblyospora connecticus via release of the intermediate copepod host, Acanthocyclops vernalis. J. Am. Mosq. Control Assoc. 1989; 5 (1): 81-85.

APPERSON CS, POWELL EE, ESSEN FV. Evaluation of a sustained release formulations of Bacillus thuringiensis (H-14) for control of Woodland Culex mosquitoes. J. Am. Mosq. Control Assoc. 1986; 2 (3): 376-378.

ARREDONDO - JIMÉNEZ JIA, LÓPEZ T, RODRIGUEZ MH, BOWN DN. Small scale field trials of Bacillus sphaericus (strain 2362) against Anopheline and Culicine mosquito larvae in Southern Mexico. J. Am. Mosq. Control Assoc. 1990; 6 (2): 300305.

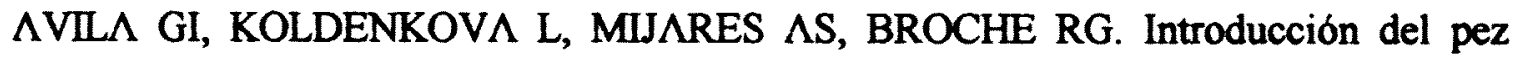
larvívoro Poecillia reticulata (Peters, 1895) (Cyprinodontiformes: Poeciliidae), agente biorregulador de culícidos en lagunas de oxidación y zanjas contaminadas en la Isla de la Juventud. Rev. Cub. Med. Trop. 1991; 43 (1): 45-59. 
AXTELL RC, GUZMAN DR. Encapsulation of the mosquito fungal pathogen Lagenidium gigantum (Oomycetes: Lagenidiales) in calcium alginate. J. Am. Mosq. Control Assoc. 1987; 3 (3): 450-459.

AXTELL RC. Principles of integrated pest management (IPM) in relation to mosquito control. Mosquito News 39(4): 709-18, 1979.

AZEVEDO JL. Melhoramento genético de fungos utilizados no controle biológico de insetos: utilização do processo parameiótico. Mem. Inst. Oswaldo Cruz 1989; 84 (Supl. III): 27-29.

BAILEY DL, LOWE RE, FOWLER JEF, DAME DA. Sterlizing and packaging males of Anopheles albimanus wiedemann for field release. Am. J. Trop. Med. Hyg. 1979; 28 (5): 902-908.

BASSI DG, WEATHERSBEE AA, MEISCH MV, INMAN ${ }^{2}$ Efficacy of Duplex and Vetobac against Anopheles quadrimaculatus larvae in Arkansas ricefields. J. Am. Mosq. Control Assoc. 1989; 5 (20): 264-266.

BECKER BK. Repensando a questão ambiental no Brasil a partir da geografia política. In: Leal MC et al. Saúde, ambiente e desenvolvimento. São Paulo: Hucitec/ Rio de Janeiro: Abrasco; V1, p 127-79, 1992.

BECNEL JJ. Prospects of microsporidia and fungi for the control of container-inhibiting mosquitoes. Symposium: Microsporidia, Fungal and Microbial Control Agents, 1992.

BERRY WJ, NOVAK GM, KHOUNLO S, ROWLEY WA, MELCHIOR GL. Efficacy of Bacillus sphaericus and Bacillus thurigiensis var. israelensis for control of Culex Pipiens and floodwater Aedes larvae in Iowa. J. Am. Mosq. Control Assoc. 1987; 3 (4): 579-582.

BLACKMORE MS, BERRY RL, FOSTER WA, WALKER ED, WILMONT TR, CRAIG, JR GB. Records os mosquito- parasitic mermithid nematodes in the Northcentral United States. J. Am. Mosq. Control Assoc. 1993; 9 (3): 338-343.

BLACKMORE MS, NIELSEN LT. Observations on the biology of Romanomermis sp. (Nematoda: Mermithidae) parasites of Aedes in Western Wyoming. J. Am. Mosq. Control Assoc. 1990; 6 (2): 229-234.

BOKLUND RJ. Mosquitofish in control programs [ Letter to the editor] J. Am. Mosq. Control Assoc. 1997; 13 (1): 99-100.

BOWLES DE, MEISCH MV, WEATHERSBEE AA, JONES JW, EFIRD P, BASSI D. Efficacy of Bacillus sphaericus formulations against Psorophora columbiae larvae in small rice plots. J. Am. Mosq. Control Assoc. 1990; 6 (4): 631- 634. 
BUZZI ZJ. Entomologia Didática. Ed. Universidade Federal do Paraná; 1985.

CARRERA M. Entomologia para Você. Ed. Chácaras e Quintas; 1956.

CASTER JL, BAILEY DL. Effects of Toxorhynchites amboinensis on laboratory-reared Aedes aegypti populations (Diptera: Culicidae). J. Med. Entomol. 1984; 21 (2): 132136.

CASTRO SDB, ARIAS AM, TELASQUEZ RC, GRANADOS R Introducción del Bacillus sphaericus cepa - 2362 (GRISELESF) para el control biológico de vectores maláricos en Guatemala. Rev. Cubana Med. Trop. 2000; 52 (1): 37-43.

CECH JJ, LINDEN AL. Comparative larvivorus performances of mosquitofish, Gambusia affinis, and juvenile sacramento blackfish, Orthodon microlepidotus, in experimental paddies. J. Am. Mosq. Control Assoc. 1987; 3 (1): 35-41.

CONSOLI RA, GUIMARÃES CT, SOUZA CP, SANTOS BS. Atividade predatória de Triserialis lineata (Hirudinea: Glossiphodinae) sobre formas imaturas de Aedes fluviatilis e Culex quinquefasciatus (Diptera: Culicidae) em laboratório. Rev. Saúde públ 1984; 18: 359-366.

CONSOLI R $\Lambda$ GB, PEREIR $\Lambda$ MH, MELO $\Lambda$ L, PEREIR $\Lambda$ LH. Belostoma micantulum Stal, 1858 (Hemiptera: Belostomatidae) as a predator of larvae and pupae of Aedes fluviatilis (Diptera: Culicidae) in laboratory conditions. Mem. Inst. Oswaldo Cruz $1989 ; 84$ (4) 577-578.

CONSOLI RAGB, SANTOS BS, LAMOUNIER MA, SECUNDINO NFC, RABINOVITCH L, SILVA CMB et al. Efficacy of a new formulation of Bacillus sphaericus 2362 against Culex quinquefasciatus (Diptera: Culicidae) in Montes Claros, Minas Gerais, Brazil. Mem. Inst. Oswaldo Cruz 1997; 92 (4): 571-573.

COOSEMANS M, MOUCHET J. Consequences of rural development on vectors and their control. Ann Soc Belg Med Trop, 70: 5-23, 1990.

CUEBAS- INCLE EL, Infection of adult mosquitoes by the entomopathogenic fungus Erynia conica (Entomophthorales: Entomophthoraceae). J. Am. Mosq. Control Assoc. $1992 ; 8$ (4): 367-371.

ESCALANTE NG, SALAS IF, DANTES HG. Field evaluation of Mesocyclops longisetus (Copepoda: Cyclopoidea) for the control of larval Aedes aegypti (Diptera: Culicidae) in Northeastern Mexico. J. Med. Entomol. 1998; 35 (5): 699-703.

FEDERICI BA. The future of microbial insecticides as vector control agents. J. Am. Control Assoc. 1995; 11(2): 260-268. 
FLEMING GA. Controle de vetores de malária: um desafio estimulante. Rev. brasil. Malariol. D. trop. $1983 ; 35: 79-83$.

FOCKS DA, SACKETT SR, DAME DA, BAILEY DL. Toxorhynchites rutilus rutilus (Diptera: Culicidae): field studies on dispersal and oviposition in the context of the biocontrol of urban container-breeding mosquitoes. J. Med. Entomol. 198320 (4): 383390.

FONSECA JFG, BROCHE RG, KOLDENKOVA YL. Capacidade depredadora de Poecilia (Lebistes) reticulata Peters, 1895 ( Cyprinodontiformes: Poecillidae) sobre larvas de Culex quinquefasciatus Say, 1823 y Aedes aegypti Linneo, 1762 (Diptera: Culicidade) en condiciones de laboratorio en Cuba. Rev. Cub. Med. Trop. 1988; 40 (1): 54-60.

FORATTINI OP. Entomologia Médica. São Paulo: Ed. USP; 1962. V- 1 p. 193.

FORATTINI OP. Entomologia Médica. São Paulo: Ed. USP; 2002.

GARCIA JJ, FUKUDA T, BECNELL JJ. Seasonality, prevalence and pathogenicity of the gregari Ascogregarine taiwanensis (Apicomplexa: Lecudinidae) in mosquitoes from Florida. J. Am. Mosq. Control Assoc. 1994; 10 (3): 413-418.

GEBARA AB. Controle integrado de mosquitos - Alguns conceitos. Rev. Bras. Entomol. 1987; 31 (3): 435-437.

GEORGE JÁ, NAGY BAL, STEWART JW. Efficacy of Dugesia tigrina (Tricladida: Turbellaria) in reducing Culex numbers in both field and laboratory. Mosquito News 1983; 43 (3): 281-284.

GOETTEL MS. Preliminary field trials with the entomopathogenic hyphomycete Tolypocladium cylindrosporum in Central Alberta. J. Am. Mosq. Control Assoc. 1987; 3 (2): 239-245.

GOETTEL MS. Studies on biossay of the entomopathogenic hypomycetes fungus Tolypocladium cylindrosporum in mosquitoes. J. Am. Mosq. Control Assoc. 1987; 3 (4): 561-567.

GROVES RL, MEISCH MV. Laboratory and field plot biossay of Bacillus saphaericus against Arkansas mosquito species. J. Am. Mosq. Control Assoc. 1996; 12 (2): 220224.

GUZMAN DR, AXTELL RC. Population dynamics of Culex quinquefasciatus and the fungal pathogen Lagenidium giganteum (Oomycetes: Lagenidiales) in stagnant water pools. J. Am. Mosq. Control Assoc. 1987; 3 (3): 442-449. 
HABIB MEM.Utilização de bactérias no controle de dípteros de importância médica. Mem. Inst. Oswaldo Cruz 1989; 84 (Supl. III): 31-34.

HARE SGF, NASCI RS. Effects of sublethal exposure to Bacillus thuringiensis var. israelensis on larval development and adult size in Aedes aegypti. J. Am. Mosq. Control Assoc. 1986; 2 (3): 325- 328.

HOBBS JH, MOLINA PA. The influence of the aquatic fern Salvinia auriculata on the breeding of Anopheles albimanus in coastal Guatemala. Mosquito News 1983; 43 (4): 456-459.

HOLCK AR, MEEK CL. Dose-mortality responses of crawfish and mosquitoes to selected pesticides. J. Am. Mosq. Control Assoc. 1987; 3 (3): 407-411.

HORNY JÁ, COTTERILL B, MLLER JR. TW. Larval mosquito control by Lagenidium giganteum. Journal of the Florida Mosquito Control Association 1992; $63(2): 82-86$.

JARONSKI S, AXTELL RC. Persistence of the mosquito fungal pathogen Lagenidium giganteum (Oomycetes: Lagenidiales) after introduction into natural habitats. Mosquito News 1983; 43 (3): 332-337.

JARONSKI ST, AXTELL RC. Effects of organic water pollution on the infectivity of fungus Lagenidium giganteum (Oomycetes: Lagenidiales) for larvae of Culex quinquefasciatus (Diptera: Culicidae): field and laboratory evaluation. J. Med. Entomol. 1982; 19 (3): 255-262.

JONES CJ e LLOYD JE. Efficacy of Baccilus thurigiensis (H-14) for larval Aedes mosquito control in intermountain meadows in Wyoming. J. Am. Mosq. Control Assoc. 1985; 1 (1): 51-55.

JONES JW, WEATHERSBEE AA, EFIRD P, MEISCH MV. Evaluation of Bacillus sphaericus 2362 against Culex quinquefasciatus in septic ditches. J. Am. Mosq. Control Assoc. 1990; 6 (3): 496- 499.

KENNY EA, RUBER E. Mermithid nematode parasites of Coquillettidia perturbans in Massachussetts. J. Am. Control Assoc. 1991; 7 (4): 663-664.

KERWIN Л, WASHINO RK. Field evaluation of Lagenidium goganteum (Oomycetes: Lagenidiales) and description of a natural epizoötic involving a new isolate of the fungus. J. Med. Entomol. 1988; 25 (6): 452-460.

KERWIN J, WASHINO RK. Ground and aerial application of the asexual satage of Lagenidium giganteum for control of mosquitoes associated with rice culture in the Central Valley of California. J. Am. Mosq. Control Assoc. 1987; 3 (1): 59-64. 
KERWIN JL, WASHINO RK. Ground and aerial application of the sexual and asexual stages of Lageniidium giganteum (Oomycetes: Lagenidiales) for mosquito control. J. Am. Mosq. Control Assoc. 1986; 2 (2): 182-189.

KNUDSEN AB, SLOOFF $R$. Vector-bome disease problems in rapid urbanization: new approaches to vector control. Bull World Health Organ 70:1-6, 1992.

KRAMER VI. Laboratory evaluation of Lagenidium giganteum (Oomycetes: Lagenidiales) in water from Contra Costa County, California, mosquito sources. J. Am. Mosq. Control Assoc. 1990; 6 (1): 79-83.

KRAMER VL, GARCIA R, COLWELL AE. An evaluation of the mosquitofish Gambusia affinis, and the inland silverside Menidia beryllina, as mosquito control agents in California wild rice fields. J. Am. Mosq. Control Assoc. 1987; 3 (4): 626632.

KRAMER VL, GARCIA R, COLWELL AE. An evaluation of Gambusia affinis and Bacillus thuringiensis var. israelensis as mosquito control agents in California wild rice fields. J. Am. Mosq. Control Assoc. 1988; 4 (4): 470-478.

LACEY LA, DAME DA. The effect of Bacillus thuringiensis var. israelensis on Toxorhynchites rutilus rutilus (Diptera: Culicidae) in the presence and absence of prey. J. Med. Entomol. 1982; 19 (5): 593-596.

LACEY LA, HEITZMAN CM, BILLODEAUX J. Beecomist- applied Ibacillus sphaericus for the control of riceland mosquitoes. J. Am. Mosq. Control Assoc. 1986; 2 (4): 548-551.

LACEY LA, INMAN A. Efficacy of granular formulations of Bacillus thuringiensis (H14) for the control of Anopheles larvae in rice field. J. Am. Mosq. Control Assoc. 1985; $1(1): 38-42$.

LACEY LA, URBNA MJ, HEITZMAN CM. Sustained release formulations of Baccilus sphaericus and Bacillus thurigiensis (H-14) for control of container-breeding Culex quinquefasciatus. Mosquito News 198444 (1): 26-32.

LAGO GM, PEREZ MD, FIGUEROA AM, GONZALEZ FAC. Resulatados de las aplicaciones en pilotaje del biolarvicida Bacillus sphaericus 2362 en criaderos de mosquitos del municipio Santa Cruz del Norte (provincia La Habana). Rev. Cub. Med. Trop. 1991; 43 (1): 39-44.

LAIRD M. The nature history of larval mosquito habitats. London: Academic Press; 1988. 
LEE DK, BHATKAR AP, VINSON SB, OLSON JK. Impact of foraging red imported fire ants (Solenopsis invicta) (Hymenoptera: Formicidae) on Psorophora columbiae eggs. J. Am. Mosq. Control Assoc. 1994; 10 (2): 163-173.

LINDEN AL, CECH JR JJ. Prey selection by mosquitofish (Gambusia affinis) in California Rice Field: effect of vegetation and prey species. J. Am. Mosq. Control Assoc. $1990 ; 6(1): 115-120$.

LORD JC, FUKUDA T. Relative potency of Bacillus thuringiensis var. israelensis and Bacillus sphaericus 2362 for Mansonia titillans and Mansonia dyari. J. Am. Mosq. Control Assoc. 1990; 6 (2): 325-327.

LORD JC. Sustaines release pellets for control of Culex larvae with Bacillus sphaericus. J. Am. Mosq. Control Assoc. 1991; 7 (4): 560-564.

LOUNIBOS LP, NISHIMURA N, DEWALD LB. Predation of Mansonia (Diptera: Culicidae) by native mosquitofish in Southerm Florida. J. Med. Entomol. 1992; 29 (2): 236-241.

LYSEWNKO OL, DAVIDSON EW, LACEY LA, YOUSTEN AA. Five new mosquito larvidal of Bacillus sphaericus from non-mosquito origins. J. Am. Mosq. Control Assoc. 1985; 1 (3): 369-371.

MARAMOROSCH K.The future of mosquito-borne diseases in the world. J, Am. Mosq. Control Assoc. 1985; 1 (4): 419-422.

MARGALIT J, DEAN D. The story of Bacillus thurigiensis var. israelensis (B.t.i.) [ Articles]. J. Am. Mosq. Control Assoc. 1985; 1 (1): 1-7.

MARTEN GG, BORDES ES, NGUYEN M. A review of operational use of Cyclopoid Copepods at the New Orleans Mosquito Control Board. J. Am. Mosq. Control Assoc. 1993; 64 (2)129-131.

MARTEN GG, NGUYEN M, MASON BJ, NGO G. Natural control of Culex quinquefasciatus larvae in residential ditches by copepod Macrocyclops albidus. Journal of Vector Ecology 2000; 25 (1): 7-15.

MARTEN GG. Elimination of Aedes albopictus from tire piles by introducing Macrocyclops albidus (Copepoda: Cyclopidae). J. Am. Mosq. Control Assoc. 1990; 6 (4): 689-693.

MARTEN GG. Evaluation of cyclopoid copepods for Aedes albopictus control in tires. J. Am. Mosq. Control Assoc. 1990; 6 (4): 681- 688. 
MATANMI BA, FEDERICI BA, MULLA MS. Fate and persistence of Bacillus saphaericus used as a mosquito larvicide in dairy wastewater lagoons. J. Am. Mosq. Control Assoc. 1990; 6 (3): 384- 389.

McLAUGHILN RE, VIDRINE MF. Comparison of three Bacillus thurigiensis serotype H-14 formulations against Psorophora columbiae. Mosquito News 1984; 44(3): 351356.

McLAUGHLIN RE, VIDRINE MF. Factors affecting distribution of Bacillus thurigiensis serotype H-14 during flooding of rice fields. J. Am. Mosq. Control Assoc. $1985 ; 1$ (3): 381-384.

MEISCH MV, FINCH MF, WEATHERSBEE AA, JONES JW, BASSI DG, BOWLES DE. Efficacy of various Bacillus thuringiensis var. israelensis formulations against Psorophora columbiae larvae as assessed in small rice plots, 1984-88. J. Am. Mosq. Control Assoc. 1990; 6 (1): 93-95.

MELLO AS, ANDRADE CF. Differential predation of the palnarian Dugesia tigrina on two mosquito species under laboratory conditions. J. Am. Mosq. Control Assoc. 2001; 17 (1): 81-83.

MERRISN TL, AXTELL RC. Field evaluation of Baccilus thurigiensis var. israelensis for control of Aedes taeniorhynchus in salt marsh pools. Mosquito News 1983; 43 (1): 84-86.

MESSIAS CL.Fungos, sua utilização para controle de insetos de importância médica e agrícola. Mem. Inst. Oswaldo Cruz 1989; 84 (Supl. III): 57-59.

MIAN LS, MULLA MS, WILSON BA. Studies on potential biological control agents of immature mosquitoes in sewage wastewater in Southern California. J. Am. Mosq. Control Assoc. 1986; 2 (3): 329-335.

MIDDAUGH DP, HESTER PG, MEISCH MV, STARK PM. Preliminary data on use of the inland silverside, Menidia beryllina to control mosquito larvae. J. Am. Mosq. Control Assoc. 1985; 1 (4): 435-441.

MIJARES AS, AVILA IG, ROSALES JR, MONTERO AS. Release of Romanomermis iyengari (Nematoda: Mermithidae) to control Aedes taeniorhynchus (Diptera:Culicidae) in Punta del Este, Isla de la Juventud, Cuba. J. Med. Entomol. 1996; 33 (4): 680-682.

MIJARES AS, BELLINI AC. Producción masiva de Romanomermis iyengari (Nematoda: Mermithidae) y su aplicación en criaderos de anofelinos en Boa Vista (Roraima), Brasil. Rev. Panam. Salud Publica 2000; 7 (3) 155-161 
MIJARES AS, BROCHE RG. Control biológico de larvas de mosquito mediante coleópteros acúaticos en condiciones de laboaratorio. Rev. Cub. Med. Trop. 1985; 37 : 354-358.

MIJARES AS, PACHECO RP, MARTÍNEZ SH. Susceptibilidad de las larvas de Aedes aegypti al, parasitismo por Romanomermis culicivorax en condiciones de laboratorio y de campo en Oaxaca, México. Rev. Panam. Salud Publica 2000; 8 (5): 299-304.

MIJARES AS, PACHECO RP. Reduction of mosquito larval densities in natural sites after introduction of Romanomermis culicivorax (Nematoda: Mermithidae) in Cuba. $\mathbf{J}$. Med. Entomol. 1997; 34 (1): 1-4.

MIKOJI GM, BOYCE TG, MUNGAI BN, COPELAND RS, HOFKIN BV, LOKER ES. Predation of aquatic satages os Anopheles gambie by the Louisiana red swamp crawfish ( Procambarus clarkii). J. Am. Mosq. Control Assoc. 1999; 15 (1): 69-71.

MIURA T, TAKAHASHI R. Predation of Microvelia pulchella (Hemiptera: Veliidae) on mosquito larvae. J. Am. Mosq. Control Assoc. 1988; 4 (1): 91-93.

MIURA T, TAKAHASHI RM. A labiratory study of predation by damselfly nymphs, Enallagma cicile, upon mosquito larvae, Culex tarsalis. J. Am. Mosq. Control Assoc. 1988; 4 (2): 129- 131.

MORSE SS. Factors in the emergence of infectious diseases. Emerg Infect Dis 1:7-15, 1995.

MULLA MS, DARWAZEH HÁ, DAVIDSON EW, DULMAGE HT, SINGER S. Larvicidal activity and field strains against mosquito larvae and their safety to nontarget organisms. Mosquito News 1984; 44 (3): 336-342.

MULla MS, DARWAZEH HÁ, DAVIDSON EW, DULMAGE HT. Efficacy and persistence of the microbial agent Baccilus sohaericus against mosquito larvae in organically enriched habitats. Mosquito News 1984; 44 (2): 166-173.

MULLA MS, DARWAZEH HÁ, TIETZE NS. Efficacy of Bacillus sphaericus 2362 formulations against floowater mosquitoes. J. Am. Mosq. Control Assoc. 1988; 4 (2): 172-174.

MULLIGAN III FS, FARLEY DG, CATON JR, SCHAEFER CH. Survival and predatory efficiency of Gambusia affinis for control of mosquitoes in underground drains. Mosquito News 1983; 43 (3): 318- 321.

NASCI RS, WRIGHT GB, WILLIS FS. Control of Aedes labopictus larvae using timerelease larvicide formulations in Louisiana. J. Am. Mosq. Control Assoc. 1994; 10 (1): $1-6$. 
NATAL D.Controle integrado de mosquitos. São Paulo; 2000. [Apostila da disciplina Controle Integrado de Mosquitos].

NAYAR JK, DJAM JC, KNIGHT JW. Susceptibility of Anopheles quadrimaculatusand other mosquitoes to Brugia patei (Nematoda: Filarioidea). Mosquito News 1984; 44 (3): 417-419.

NELSON SM, KEENAN LC. Use of na indigenous fish species, Fundulus zebrinus, in a mosquito abatement program: a field comparison with the mosquitofish, Gambusia affinis. J. Am. Mosq. Control Assoc. 1992; 8 (3): 301-304.

NETO ALR, OLIVEIRA CM. Controle biológico de culicídeos e simulídeos: inseticidas bacterianos. Rev. brasil. Malariol. D. trop. 1985; 37: 61-75.

NETO AR, SILVEIRA SM. Uso de inseticidas bacterianas para o controle de culicídeos e simulídeos no Rio Grande do Sul. Mem. Inst. Oswaldo Cruz 1989, 84 (Supl. III): 3945 .

NOVAK RJ, GUBLER DJ, UNDERWOOD D.Evaluation of slow-release formulations of themephos (ABATE) and Baccilus thuringiensis var. israelensis for the control of Aedes aegypti in Puerto Rico. J. Am. Mosq. Control Assoc. 1985; 1 (4): 449-453

ODUM EP. Ecologia. Editora Guanabara Koogans S.A., 1988.

OFFILL YA, WALTON WE. Comparative efficacy of the threespine stickleback (Gasterosteus aculeatus) and the mosquitofish (Gambusia affinis) for mosquito control. J. Am. Mosq. Control Assoc. 1999; 15 (3): 380-390.

ORGANIZAÇÃO MUNDIAL DE SAÚdE. Problemas técnicos de lãs operaciones de lucha antivectorial. Primer informe del Comité de expertos de la OMS em biologia de vetores e lucha antivectorial. Serie de Informes Técnicos 603, OMS, Genebra, 1977.

ORGANIZAÇÃO MUNDIAL DE SAÚDE. Manual de ordenamiento del medio para la lucha contra los mosquitos. Publicacion en offset 66, 1984.

ORR BK, RESH VH. Experimental Test of influence of aquatic macrophyte cover on the survival of Anopheles larvae. J Am Mosq Control Assoc 5: 579-85, 1989.

PACHECO RP, MIJARES AS, MARTÍNEZ SH, AMBROSIO GF. Susceptibilidad de las larvas de Anophelew pseudopunctipennis al parasitismo del nematodo Romanomermis iyengari (Nematoda: Mermithidae), no estado de Oaxaca, México. Rev. Cub. Med. Trop. 1998; 50 (3): 199-202. 
PATEL KJ, RUEDA LM, AXTELL RC. Comparisons of different types and concentrations of alginates for encapsulation of Lagenidium giganteum (Oomycetes: Lagenidiales), a fungal pathogen of maosquito larvae. J. Am. Mosq. Control Assoc. 1990; 6 (1): 101-104.

PERICH MJ, BOOBAR LR, STIVERS JC, RIVERA LA. Field evaluation of four bioration larvicide formulations against Anopheles albimanus in Honduras. Medical and Veterinary Entomology 1990; 4: 393-396.

PERICH MJ, CLAIR PM, BOOBAR LR. Integrated use of planaria (Dugesia dorotocephala) and Bacillus thuringiensis var. israelensis against Aedes taeniorhynchus: a laboratory biossay. J. Am. Mosq. Control Assoc. 1990; 6 (4): 667 671.

PERICH MJ, ROGERS JT, BOOBAR LR. Efficacy of arosurf msf and formulations of Bacillus thuringiensis var. israelensis against Anopheles albimanus: laboratory biossay. J. Am. Mosq. Control Assoc. 1987; 3 (3): 485-488.

RAWLINS SC, MARTINEZ R, NIMBLETT A. Consumption of Aedes aegypti larvae by Poecillia reticulata (Guppies) and factors which affect the productivity of the larvivorous fish in drum environments. Journal of the Florida Mosquito Control Association 1993; 64 (2): 125-128.

RAWLINS SC, MARTINEZ E, WILTSHIRE S, CLARKE D, PRABHAKAR P, SPINKS M. Evalition of carobbean strains of Macrocyclops and Mesocyclops (Cyclopoida: Cyclopidae) as biological control tools for the dengue vector Aedes aegypti. J. Am. Mosq. Control Assoc. 1997; 13 (1): 18-23.

REARDON TP, LUNT SR. Parasitism of adult Aedes vexans by a mermithid (Nematoda: Mermithidae) in Iowa. J. Am. Mosq. Control Assoc. 1989; 5 (3): 446-447.

REGIS L, FURTADO AF, OLIVEIRA CMF, BEZERRA CB, SILVA LRF, ARAÚJO J, MACIEL A, SILVA-FILHA MH, SILVA S. Controle integrado do vetor da filariose com participação comunitária, em uma área urbana do Recife, Brasil. Cad. Saúde Públ. $1996 ; 12(4): 473-482$.

REGIS L, SILVA-FILHA MHNL, OLIVEIRA CMF, RIOS EM, SILVA SB, FURTADO AF. Integrated control measures against Culex quinquefasciatus, the vector of filariasis in Recife. Mem. Inst. Oswaldo Cruz 1995; 90 (1): 115-119.

RODRIGUES IB, TADEI WP, DIAS JMCS. Studies on the Bacillus sphaericus larvicidal activity against malarial vector species in Amazonia. Mem. Inst. Oswaldo Cruz 1998; 93 (4): $441-444$. 
RUAS-NETO AL, SILVEIRA SM, COLARES ERC. Mosquito control based on larvicides in the state of Rio Grande do Sul, Brazil: choice of the control agent. Cad. Saúde Públ. 1994; 10 (2): 222-230.

RUEDA LM, PATEL KJ, AXTELL RC. Efficacy of encaosulated Lagenidium giganteum (Oomycetes: Lagenidiales) against Culex quinquefasciatus and Aedes aegypti larvae in artificial containers. J. Am. Mosq. Control Assoc. 1990; 6 (4): 694-699.

RUSSO R. Comparison of predatory behavior in fivespecies of Toxorhynchites (Diptera: Culicidae). Ann. Entomol. Soc. Am. 1986; 79: 715-722.

SANDOSKI CA, YATES MM, OLSON JK, MEISCH MV. Evaluation of beecomist applied Bacillus thurigiensis (H-14) against Anopheles quadrimaculatus larvae in rice fields. J. Am. Mosq. Control Assoc. 1985; 1 (3): 316-319.

SANTOS LU, Andrade CFS. Survey of cyclopds (Crustacea, Copepoda) in Brazil and preliminary screening of their potencial as dengue vector predators. Rev Saúde Pública 31: 221-6, 1997.

SANTOS LU, ANDRADE FS, CARVALHO GA. Biological control of Aedes albopictus (Diptera: Culicidae) larvae in trap tyres by Mesocyclops longisetus (Copepoda: Cyclopidae) in two field trials. Mem. Inst. Oswaldo Cruz 1996; 91 (2): 161-162.

SANTOS LU, SOUZA AB, ANDRADE CFS, SOUZA CEP. Uso de Bacillus thuringiensis (H-14) como agente de controle de mosquitos em um cemitério. Rev. Pat. Trop. $1994 ; 23$ (2): 151-158.

SAVAGE HM, REJMANKOVA E, ARREDONDO-JIMENEZ JI., ROBERTS DR, RODRIGUEZ MH. Limnological and botanical characterization of larval habitats for two primary malarial vectors, Anopheles albimanus and Anopheles pseudopunctipennis, in coastal areas of Chiapas State, México. J Am Mosq Control Assoc 6: 612-20, 1990.

SCHAPER S, HERNANDEZ F, SOTO L. La lucha contra el dengue: control biológico de larvas de Aedes aegypti empleando Mesocyclops thermocyclopoides (Crustacea). Rev. Cost. de Ciencias Médicas 1998; 19 (1,2): 119-125.

SCHOFIELD CJ. Environmental change: descripton or prediction ?. Ann Soc Belge Med Trop 70: 1-3, 1990.

SCHREIBER ET, HALLMON CF, ESKRIDGE KM, MARTEN GG. Effects of Mesocyclops longisetus (Copepoda: Cyclopidae) on mosquitoes that inhabit tires: influence of litter type, quality and quantity. J. Am. Mosq. Control Assoc. 1996; 12 (4): 688-694. 
SCHREIBER ET, TURNER WL, LOPEZ AM, HALLMON CF, MARTEN GG. Evaliation of two cyclopoid for Aedes albopictus control in tires the Panhandle alt low introduction rates. Journal of the Florida Mosquito Control Association 1993; 64 (2): 73-77.

SCHRIEBER ET E JONES C. Na overview of biological control. University of Florida, Cooperative Extension Service, Institute of Food and Agricultural Sciences, http://edis.ifas.ufl.edu/BODY IN061.

SERVICE MW. Agricultura development and arthropod-borne disease: a review. Rev Saúde Pública 25:165-78, 1991.

SHERRAT TN, TIKASINGH ES. A laboratory investigation of mosquito larval predation by Toxorhynchites moctezuma on Aedes aegypti. Medical and Veterinary Entomology 1989; 3: 239-246.

TIETZE NS, HESTER PG, SHAFFER KR, PRESCOTT SJ, SCHREIBER ET. Integrated management of waste tire mosquitoes utilizing Mesocyclops longisetus (Copepoda: Cyclopidae), Bacillus thuringiensis var. isaraelensis, Baccilus sphaericus, and, methoprene. J. Am. Mosq. Control Assoc. 1994; 10 (3): 363-373.

TIETZE NS, MULLA MS. Biological control of Culex mosquitoes (Diptera: Culicidae) by the tadpole shrimp, Triops longicaudatus (Notostraca: Triopsidae). J. Med. Entomol. $1991 ; 28$ (1): 24-31.

TIETZE NS, MULLA MS. Influence of tadpole shrimp, Triops longicaudatus (Notostraca: Triopsidae), stocking rate on Culex tarsalis development in experimental field microcosms. J. Am. Mosq. Control Assoc. 1990; 6 (2): 265-269.

TODD RG, GIGLIOLI MEC. The failure of Gambusia puncticulata and other minnows to control Aedes taeniorhynchus in mangrove swamp on Grand Cayman, W. I.. Mosquito News 1983; 43 (4): 419-425.

UNDEEN AH, DAME DA. Measurement of the effect of microsporidiam pathogens on mosquito larval mortality under artificial field conditions. [ Operation and scientific notes]. J. Am. Mosq. Control Assoc. 1987; 3 (1): 91-93.

URBINATTI PR, Imaturos de mosquitos (Diptera, Culicidae): caracterização de criadouros - Parque Ecológico do Tietê, Guarulhos, Såo Paulo. [Dissertação de Mestrado - Faculdade de Saúde Pública da USP], 2000.

VAN ESSEN FW, HEMBREE SC. Laboratory biossay of Bacillus thuringiensis israelensis against all instar of Aedes aegypti and Aedes taeniorhynchus larvae. Mosquito News 1980; 40 (3): 424-431. 
VARGAS LG, VARGAS MV. Acción depredadora en el laboratorio de Priapichthys annectens (Regan) (Pisces: Poeciliidae) sobre larvas de Culex spp. Rev. Biol. Trop. $1985 ; 33$ (2): 133-136.

WALKER DE, POIRIER SJ VELDMAN WT. Effects of Ascogregarina barretti (Eugregarinida: Lecudinidae) infection on emergence sucess, development time, and size of Aedes triseriatus (Diptera: Culicidae) in Microcosms and tires. J. Med. Entomol. 1987; 24: 303-309.

WALKER TW, MEEK CL, WRIGHT VL. Establish and recycling of Romanomermis culivorax (Nematoda: Mermithidae) in Louisiana ricelands. J. Am. Mosq. Control Assoc. $1985 ; 1$ (4): 468-473.

WALLACE FL, WILLIANS DC, GWINN TA. A new method of testing Bacillus thuringiensis var. israelensis $(\mathrm{H}-14)$ formulations on Aedes taeniorhynchus in na abandoned rice impoundment in South Carolina. [ Operational and scientific notes]. J. Am. Mosq. Control Assoc. 1989; 5 (4): 593-595.

WASHUBURN JO, EGERTER DE, ANDERSON JR, GARY AS. Density reduction in larval mosquito (Diptera: Culicidae) populations by interactions between a parasict ciliate (Ciliophora: Tetrahymenidae) and opportunistc fungal (Oomycetes: Pythiaceae) parasite. J. Med. Entomol. 1988; 25 (5): 307-314.

WILMOT TR, ALLEN DW, HARKANSON BA. Field trial of two Bacillus thuringiensis var. israelensis formulations for control of Aedes species mosquitoes in Michigan Woodlands. J. Am. Mosq. Control Assoc. 1993; 9 (3): 344-345.

WORLD HEALTH ORGANIZATION. Fifth meeting on the scientific working group on biological control of vector. Geneva, 1981; P. 81-3.

WORLD HEALTH ORGANIZATION. Report of a meeting on standardization and industrial development of microbiol control agents. Genebra, 1979 p.tdr/bcv/79.01 (mimeografado).

WORLD HEALTH ORGANIZATION. The role of biological agents in integrated vector control and the formulation of protocols for field testing of biologocal agents. Geneva, 1982; p. 82-3

WORLD HEALTH ORGANIZATION. Report of the seventh meeting of scientific working group on biological control of vectors. World Health Organization, UNDP/ World Bank/ WHO Special Programe for Research and Training in Tropical Diseases, Genebra, 5-9 March, 1984. 